\title{
Differential Expression of Glutamate Receptor Subunits in the Nervous System of Caenorhabditis elegans and Their Regulation by the Homeodomain Protein UNC-42
}

\author{
Penelope J. Brockie, David M. Madsen, Yi Zheng, Jerry Mellem, and Andres V. Maricq \\ Department of Biology, University of Utah, Salt Lake City, Utah 84112-0840
}

In almost all nervous systems, rapid excitatory synaptic communication is mediated by a diversity of ionotropic glutamate receptors. In Caenorhabditis elegans, 10 putative ionotropic glutamate receptor subunits have been identified, a surprising number for an organism with only 302 neurons. Sequence analysis of the predicted proteins identified two NMDA and eight non-NMDA receptor subunits. Here we describe the complete distribution of these subunits in the nervous system of $C$. elegans. Receptor subunits were found almost exclusively in interneurons and motor neurons, but no expression was detected in muscle cells. Interestingly, some neurons expressed only a single subunit, suggesting that these may form functional homomeric channels. Conversely, interneurons of the locomotory control circuit (AVA, AVB, AVD, AVE, and PVC) coexpressed up to six subunits, suggesting that these subunits interact to generate a diversity of heteromeric glutamate receptor channels that regulate various aspects of worm movement. We also show that expression of these subunits in this circuit is differentially regulated by the homeodomain protein UNC-42 and that UNC-42 is also required for axonal pathfinding of neurons in the circuit. In wild-type worms, the axons of AVA, AVD, and AVE lie in the ventral cord, whereas in unc-42 mutants, the axons are anteriorly, laterally, or dorsally displaced, and the mutant worms have sensory and locomotory defects.

Key words: glutamate receptor; neuron; neural circuit; development; mechanosensation; homeodomain transcription factor; Caenorhabditis elegans; locomotion; glr-1; unc-42
Glutamate is a neurotransmitter that is required for synaptic communication in vertebrate and invertebrate nervous systems. Signaling by glutamate is mediated by a large and diverse number of receptors that include ionotropic receptors that mediate rapid excitatory neurotransmission. Ionotropic glutamate receptors belong to either the NMDA family, which contains receptors that are selectively gated by the agonist NMDA, or the non-NMDA family, which contains receptors that are gated by the agonists AMPA and kainate (Dingledine et al., 1999; Hollmann, 1999). In vertebrates, 18 subunits have been identified, allowing for combinatorial complexity and the formation of heteromeric receptors that have different functional properties (Hollmann, 1999). Functional receptors are believed to be composed of either four or five subunits of the same subtype (AMPA, kainate, or NMDA) (Premkumar and Auerbach, 1997; Rosenmund et al., 1998; Dingledine et al., 1999). NMDA receptors contain the NR1 subunit and at least one NR2 subtype (Dunah et al., 1998), AMPA receptors contain from one to three different receptor subunits (Wenthold and Roche, 1998), and kainate receptors can function as homomers or heteromers (Paternain et al., 2000). Many of these receptor subunits are coexpressed in neurons, and in some neurons receptor subunits are differentially distributed at

\footnotetext{
Received Aug. 9, 2000; revised Nov. 22, 2000; accepted Dec. 12, 2000.

This research was supported in part by the Sloan Foundation, by National Institutes of Health Grant NS35812, and by a University of Utah Graduate Research Fellowship (P.J.B.). We thank M. Vetter and members of the Maricq laboratory for comments on this manuscript. We also thank C. Bargmann for assistance with cell identifications and for helpful discussions, the $C$. elegans sequencing consortium for cosmid clones, Chris Rongo and Josh Kaplan for nuIs25, the Caenorhabditis Genetic Center for some nematode strains, and the HCI DNA Sequencing Core Facility.

Correspondence should be addressed to Dr. Andres Villu Maricq, Department of Biology, University of Utah, 257 South 1400 East, Salt Lake City, UT 84112-0840. E-mail: maricq@biology.utah.edu.

Copyright (C) 2001 Society for Neuroscience $\quad 0270-6474 / 01 / 211510-13 \$ 15.00 / 0$
}

synapses (Petralia et al., 1999b). Presumably, individual neurons express different combinations of receptor subunits, and this complexity is required for signal processing in the nervous system.

Invertebrate nervous systems also appear to use multiple subtypes of glutamate receptor subunits. Analysis of the genomes of both Drosophila melanogaster and Caenorhabditis elegans has revealed large families of genes that encode potential ionotropic glutamate receptor subunits (Littleton and Ganetzky, 2000). To address questions of receptor complexity, composition, and organization at the level of individual neurons, we have examined the expression and regulation of ionotropic glutamate receptor subunits in the nervous system of $C$. elegans.

In $C$. elegans, the command interneurons form part of the locomotory control circuit and are required for the escape response to tactile stimuli (Chalfie et al., 1985; White et al., 1986). Ablation of neurons in this circuit causes uncoordinated movement and defects in responses to tactile stimuli (Chalfie et al., 1985). Furthermore, the intrinsic activity of this circuit controls the duration of forward and backward movements even in the absence of sensory inputs (Zheng et al., 1999). Processing of tactile sensory information is dependent on the non-NMDA-type ionotropic glutamate receptor subunit GLR-1. This subunit is expressed in the command interneurons and is required for the worm to back away from a touch to the nose (Hart et al., 1995; Maricq et al., 1995). However, it is not known whether GLR-1 forms a homomeric receptor or a heteromeric complex with other receptor subunits.

In a subset of the command interneurons, GLR-1 expression is dependent on the homeodomain protein UNC-42 (Baran et al., 1999). unc-42 mutants have particularly interesting defects, including sensory deficits, uncoordinated movement, and a dis- 
rupted backward escape response that is similar to that observed in worms in which the command interneurons are ablated. The phenotype of unc-42 mutants is much more severe and pleiotropic than is that of $g l r-1$ mutants, suggesting that unc-42 may also regulate the expression of other genes encoding glutamate receptors, thereby contributing to the severity of the locomotory phenotype observed in unc-42 mutants.

Here we describe 10 ionotropic glutamate receptors that are expressed in the nervous system of $C$. elegans. The receptor subunits can be categorized into NMDA and non-NMDA subtypes and are expressed in a variety of interneurons and motor neurons that suggest their involvement in the control of movement, thermotaxis, and pharyngeal function. We have also characterized the regulation of receptor expression and shown that the expression of GLR-4 and GLR-5 is also dependent on the homeodomain protein UNC-42. Furthermore, we show that connections made by the "backward" command interneurons are disrupted in unc-42 mutants, suggesting that defects in synaptic wiring of these interneurons are the probable cause of the unc-42 phenotype.

\section{MATERIALS AND METHODS}

Strains. Nematodes were grown at $20^{\circ} \mathrm{C}$ under standard conditions that included uncrowded conditions and the presence of ample food (the Escherichia coli strain OP50). Wild-type nematodes were C. elegans strain N2. Mutant strains were obtained from the Caenorhabditis Genetic Center.

cDNA clones and expression constructs. Using degenerate oligonucleotide primers designed to amplify conserved regions of ionotropic glutamate receptors, we amplified DNA fragments from first-strand mixedstage $C$. elegans cDNA that encoded portions of $g l r-3$ and $g l r-5$. These partial gene products were used to screen cDNA libraries at high stringency. After screening $\sim 10^{6}$ clones, we obtained several partial cDNAs for each gene, indicating that mRNA encoding these glutamate receptor subunits is present at relatively low levels. Hence, we were unable to isolate full-length cDNAs using this approach. We also searched the published $C$. elegans genome for genes related in sequence to $g l r-1, g l r-3$, and $g l r-5$ and identified seven additional genes that appeared to encode glutamate receptor subunits (see below). Partial cDNA clones were amplified from first-strand cDNA generated from mixed-stage N2 worms. Oligonucleotide primers were designed to amplify sequence that encoded a highly conserved region found in ionotropic glutamate receptor subunits. The PCR products were then subcloned into pCR2.1 (Invitrogen, San Diego, CA) and sequenced.

Green fluorescent protein (GFP) fusions with $g l r-3, g l r-4, g l r-6, g l r-7$, $g l r-8$, and $n m r-2$ were made by PCR amplification of a genomic DNA fragment that included $\sim 5-7 \mathrm{~kb}$ of upstream regulatory sequence followed by coding sequence terminating immediately upstream of that encoding TMIII (see Figs. 1, 4). The PCR products were subcloned into one of four GFP expression vectors: pPD95.75, pPD95.77, pPD95.79, or pPD95.81 (gifts from A. Fire). Partial, rather than full-length, GFP fusions were made to achieve maximum GFP fluorescence intensity while still including introns that might contain intragenic regulatory regions. For those subunits in which both a full-length fusion and a partial fusion have been made ( $g l r-1$ and $n m r-1$ ) there was no difference in expression pattern between the two transgenes. glr-1::GFP and $g l r-5:: G F P$ were full-length GFP fusions. $n m r-1:: G F P$ (see Fig. 5) was a partial fusion that included $5 \mathrm{~kb}$ of upstream regulatory sequence followed by the first five codes fused in-frame with GFP. The following plasmids were used: pPB45 ( $g l r-1:: G F P)$, GFP excised from pPD119.45 (A. Fire) and inserted into a HindIII site of pV1 ( $g l r-1$ genomic clone), inserting GFP 16 amino acids upstream of the GLR-1 C terminal; pMJ3 ( $g l r-2:: G F P)$, the XhoI-XmaI fragment from pV29 ( $g l r-2$ genomic clone) subcloned into pPD95.79, truncating the last 13 codons of the Genefinder-predicted $g l r$-2-coding sequence; pDM46 ( $g l r-7:: G F P)$, a 6.7 kb PCR product subcloned into the PstI and XmaI sites of pPD95.75, fusing GFP after S191 (for amino acid numbers, see those in Fig. 1); pDM38 ( $g l r-4:: G F P$ ), a $15.9 \mathrm{~kb}$ PCR product subcloned into the SalI and BamHI sites of pPD95.75, fusing GFP after A196; pDM4 ( $g l r-3:: G F P)$, an $11.9 \mathrm{~kb}$ PCR product subcloned into the $S p h \mathrm{I}$ and $X b a \mathrm{I}$ sites of pPD95.77, fusing GFP after S190; pYZ4 ( $g l r-5:: G F P)$, a 12 kb PCR product amplified from cosmid ZC196 and subcloned into SphI and BamHI sites of pPD95.77, fusing GFP immediately upstream of the Genefinder-predicted stop codon; pDM42 (glr-6::GFP), a 15 kb PCR product subcloned into the $S p h \mathrm{I}$ and $X b a \mathrm{I}$ sites of pPD95.75, fusing GFP after T184; pDM41 ( $g l r-8:: G F P$ ), a $12.5 \mathrm{~kb}$ PCR product subcloned into the SalI and BamHI sites of pPD95.77, fusing GFP after S186; pPB1 ( $n m r-1:: G F P$ ), a $5 \mathrm{~kb}$ PCR product subcloned into the SphI and SalI sites of pPD95.81, fusing GFP after the first five codons predicted by Genefinder; pPB17 (nmr-2::GFP), an $8 \mathrm{~kb}$ product subcloned into the $S p h \mathrm{I}$ and $X m a \mathrm{I}$ sites of pPD95.75, fusing GFP after S221; and pPB38, a $4.6 \mathrm{~kb}$ genomic fragment that encodes UNC-42 subcloned into the KpnI and NotI sites in MCSII of pV145.

Transgenic strains. Transgenic strains were generated by microinjection of lin-15(n765ts) mutants to achieve germ line transformation (Mello et al., 1991). Strains that expressed GFP fusions to the various glutamate receptor subunits were coinjected with $40 \mathrm{ng} / \mu \mathrm{l}$ of the plasmid pJM23 (lin-15 rescuing plasmid) (Clark et al., 1994) and $60 \mathrm{ng} / \mu \mathrm{l}$ of one of the plasmids described above (pMJ3, pYZ4, pDM38, pDM4, pDM46, pDM42, pDM41, pPB1, pPB45, or pPB17). Transgenic lines were identified by rescue of the Muv (multiple vulva) phenotype of lin-15(n765ts) mutants. Multiple independent extragenic lines were generated for each transgenic strain. Rescue of unc-42(e270) mutants was achieved by coinjecting unc-42(e270); lin-15(n765ts) worms with pJM23, pPB1, and pPB38, each at $40 \mathrm{ng} / \mu \mathrm{l}$. $g l r-1:: G F P$; unc-42(e270) was obtained by crossing unc-42 mutants with transgenic worms expressing an integrated glr-1::GFP transgene (nuIs25) (Rongo et al., 1998).

Sequence analysis and alignments. To identify genes encoding potential ionotropic glutamate receptors, we used the tblastn BLAST algorithm (Altschul et al., 1997) to search the C. elegans genomic sequence database for genes similar in sequence to C. elegans GLR-1 (Maricq et al., 1995). This search revealed genes on 12 cosmids that encoded potential glutamate receptors. Each of these predicted gene products was used to retblastn the $C$. elegans genomic sequence. In this manner we arrived at a total of 15 potential genes, including the 10 subunits described in this manuscript. In general, tblastn searches using any of the 10 subunits identified the other 9 subunits. For each putative C. elegans glutamate receptor subunit, a BLAST search of the National Center for Biotechnology Information protein database returned a closest match to an ionotropic glutamate receptor subunit. The five additional open reading frames identified by our tblastn searches were on cosmids C08B6.5 (Z72502), F59E12.8 (AF003386), Zk867.2 (U41039), W02A2.5 (Z82286), and T25E4.2 (U23411). However, the predicted peptide encoded by these ORFs showed low sequence identity with ionotropic glutamate receptors (the highest identity was to Delta subtypes) and exhibited significant divergence of the highly conserved SYTANLAAF region found in essentially all known ionotropic glutamate receptor subunits (Hollmann, 1999). Thus, we did not analyze the expression of these putative receptors.

Analysis of the amino acid sequences of glutamate receptor subunits was performed using the CLUSTALW program (Thompson et al., 1994) and the Kimura adjustment for multiple amino acid substitutions in the protein sequences (Kimura, 1983). Phylogenetic analysis of the aligned protein sequences was performed using PHYLIP (Felsenstein, 1989). Confidence in the unrooted phylogenetic tree was estimated by bootstrap analysis of 500 replicates. To eliminate length bias, analysis of all glutamate receptors was limited to the $\sim 400$ amino acid region beginning at the start of the S1 ligand-binding region and extending to the end of TMIV. The percentage of sequence identity between pairs of glutamate receptor subunits was calculated using the ALIGN program (GENESTREAM network server IGH, Montpellier, France). The following glutamate receptor subunits (accession number) were used for sequence analysis: Rat, GluR1 (M36418), GluR2 (M36419), GluR3 (M36420), GluR4 (M36421), GluR5 (P22756), GluR6 (P42260), GluR7 (P42264), KA1 (JS0685), KA2 (Z11581), delta1 (Z17238), delta2 (Z17239), NR1 (X63255), NR2A (M91561), NR2B (M91562), NR2C (M91563), NR2D (D13213), and NR3A (L34938); D. melanogaster, GluR1(M97192), GluR2 (M73271), and NR1 (S33754); Arabidopsis thaliana, AtGLR1 (AF079998), AtGLR2 (AF079999), AtGLR3 (AF007271), and AtGLR4 (AC000098) (Lam et al., 1998); and C. elegans, GLR-1 (U34661), GLR-2 (AF318606), GLR-3 (AF318607), GLR-4 (AF318608), GLR-5 (AF318609), GLR-6 (AF318610), GLR-7 (AF318611), GLR-8 (AF318612), NMR-1 (AF318613), and NMR-2 (AF318614).

Behavioral assays. Nose touch assays were performed as described previously (Kaplan and Horvitz, 1993). Worms were transferred to a plate that was lightly seeded with a uniform lawn of bacteria (E. coli 
strain OP50). A fine hair was placed on the surface of the agar in front of the path of the worm. The number of backing responses in 10 consecutive trials was determined for each worm. Anterior and posterior body touch assays were performed as described previously. By the use of an eyelash, anterior or posterior regions of worms were gently stroked, and the resulting backward or forward movement was noted (Chalfie et al., 1985).

Microscopy. Epifluorescence images were acquired using a Zeiss Axioskop microscope and a Princeton Instruments Micromax chargecoupled device camera. Confocal images were acquired using an Optiphot-2 microscope (Nikon) and a Bio-Rad Confocal Imaging System.

\section{RESULTS}

\section{Both NMDA and non-NMDA classes of ionotropic glutamate receptors are expressed in C. elegans}

We have identified by sequence similarity searches (BLAST) 10 genes encoding putative glutamate receptor subunits in C. elegans (see Materials and Methods). glr-1 has been described and encodes a subunit most similar to the non-NMDA receptor subtypes (Hart et al., 1995; Maricq et al., 1995). We have cloned partial cDNAs for the remaining nine receptor subunits. These genes were located on linkage groups I, II, III, V, and X (see Table 2). Although some genes were closely spaced ( $g l r-1$ and $g l r-2$ were separated by $\sim 0.1$ map units), the receptors did not reside in clusters. We designed oligonucleotide primers to amplify cDNAs predicted to encode a highly conserved region of $\sim 400$ amino acids for each of the nine new receptor subunits. This region includes the predicted transmembrane segments, pore region, and ligand-binding regions (Stern-Bach et al., 1994). Sequence alignments of these predicted polypeptides revealed many of the conserved regions and specific amino acid residues that are found in ionotropic glutamate receptors (Fig. 1). Overall, each of the predicted $C$. elegans subunits has the highest amino acid identity with members of a particular class of vertebrate glutamate receptor subunits (Table 1; indicated in bold). For example, GLR-2 has the highest identity to AMPA subtypes, GLR-3 to kainate subtypes, and NMR-1 to NMDA subtypes.

The topological arrangement of each protein is predicted to be similar to that of other NMDA and non-NMDA receptors. We identified four hydrophobic regions, three of which are predicted to be transmembrane domains (Fig. 1, TMI, TMIII, and TMIV). TMII, the pore-forming region, is a reentrant loop that does not traverse the membrane (Hollmann et al., 1994) and contains amino acids that have been shown to modulate channel permeability in mammalian ionotropic glutamate receptors (Hollmann, 1999). In mammals, a conserved glutamine in TMII is a key determinant of rectification and calcium permeability in nonNMDA receptors (Fig. 2) (Hume et al., 1991; Verdoorn et al., 1991). In a subset of receptor subunits, the conserved glutamine can be converted to an arginine by a process of RNA editing (Sommer et al., 1991). Receptors that contain a subunit with an arginine at this position have a significantly reduced calcium permeability (Burnashev et al., 1992). In C. elegans, most of the non-NMDA-type subunits contain the conserved glutamine in TMII. Because both the genomic and cDNA sequences encode for the same amino acids in TMII, RNA editing of the conserved glutamine is unlikely or rare. However, within the genomic sequence two of the receptors have a basic amino acid substituted for the conserved glutamine in TMII; GLR-5 has a lysine and GLR-6 has an arginine, suggesting that in these cases the alternate edited form is genomically encoded. In contrast, GLR-7 has a proline substituted for glutamine. The effect of these changes is difficult to predict but is likely to affect the conductance of the channel. Like other glutamate receptors, two separated regions in the protein ( $\mathrm{S} 1$ and $\mathrm{S} 2$ ) have a strong identity to bacterial amino acid-binding proteins and are believed to be required for ligand binding (Nakanishi et al., 1990; Kuryatov et al., 1994; Stern-Bach et al., 1994; Armstrong et al., 1998) (Fig. 1). Other regions show conserved features of glutamate receptors, including a nine amino acid sequence in TMIII (SYTANLAAF) that is found in essentially all ionotropic glutamate receptors (Fig. 2). The third alanine in this sequence is conserved among all known receptor subunits. Mutating this alanine to a threonine in selected subunits results in a constitutively conducting ionotropic receptor (Zuo et al., 1997; Zheng et al., 1999).

The relationship between the putative $C$. elegans and known vertebrate glutamate receptor subunits was analyzed by generating a neighbor-joining tree of receptor subunits (Fig. 3). Clear groupings of the subunits can be distinguished. Thus, GLR-1 and GLR-2 group together and are most similar to rat AMPA receptors. GLR-3 and GLR-4, and more weakly GLR-5 and GLR-6, also group together. GLR-3-GLR-7 are clearly non-NMDA receptor subunits but cannot be obviously classified into pharmacological subtypes. GLR-8 is the farthest outlier and is even more divergent than glutamate receptors identified in Arabidopsis. NMR-1 groups with rat NR1 and Drosophila NR1, and NMR-2 groups with rat NR2 receptors.

\section{Many neurons in C. elegans express multiple glutamate receptor subunits}

To determine which cells in $C$. elegans expressed a particular glutamate receptor subunit, we examined transgenic worms that expressed chimeric fusion proteins to the reporter molecule GFP (Chalfie et al., 1994). Typically, GFP was fused in-frame to the glutamate receptor subunit following the predicted second transmembrane domain (Fig. 4; see Materials and Methods). The expression of each chimeric protein was controlled by $\sim 5 \mathrm{~kb}$ of upstream sequence. In previous experiments we found that the expression pattern of GFP controlled by $5 \mathrm{~kb}$ of $g l r-1$ upstream sequence did not differ from the pattern observed when GFP was fused to a partial or full-length GLR-1 protein (Maricq et al., 1995; Zheng et al., 1999). However, to minimize the risk of disrupting possible intragenic control elements, we included most of the predicted introns in each construct (Fig. 4). For nmr-1, we show the expression pattern of a partial fusion to NMR-1. The neurons identified by this construct were identical to those that expressed a full-length fusion protein that showed considerably weaker GFP expression (data not shown). Using these constructs, we were able to observe reproducible GFP expression in transgenic strains.

\section{Ionotropic glutamate receptor subunits were expressed in a locomotory control circuit and in a thermosensory circuit}

Many of the glutamate receptor subunits were found to be expressed in the command interneurons that control worm locomotion (Fig. 5). For example, the neuron AVA expresses both the non-NMDA subtypes GLR-1, GLR-2, GLR-4, and GLR-5 and the NMDA subtypes NMR-1 and NMR-2. Other command interneurons expressed various subsets of these subunits (Table 2). Several patterns emerged from the expression data. First, the NMDA-type receptor subunits NMR-1 and NMR-2 were always coexpressed and were found in a relatively small number of neurons that included four of the five command interneurons. Second, many neurons expressed multiple non-NMDA receptor subunits in various combinations. For example, AVB expressed 


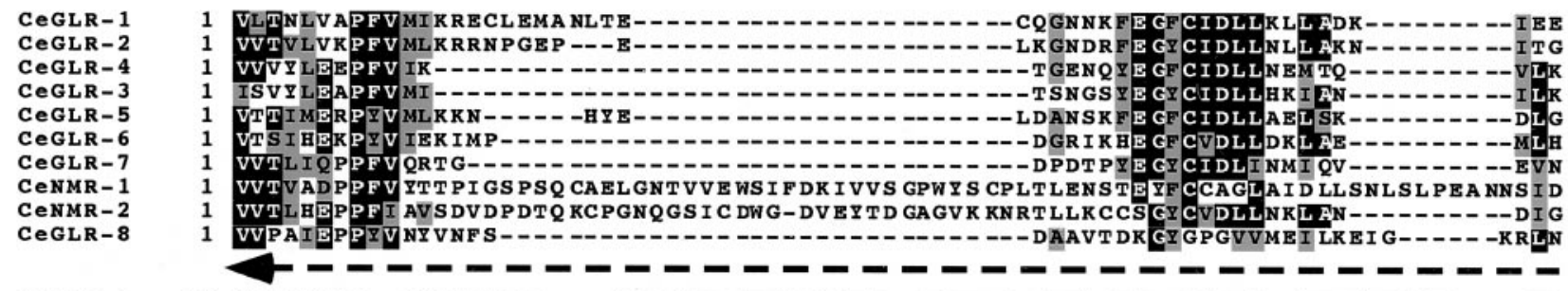

CeGLR-1

CeGLR-2

CeGLR- 4

CeGLR-3

CeGLR-5

CeGLR-6

CeNuR-1

CeNMR-2

CEGLR-8
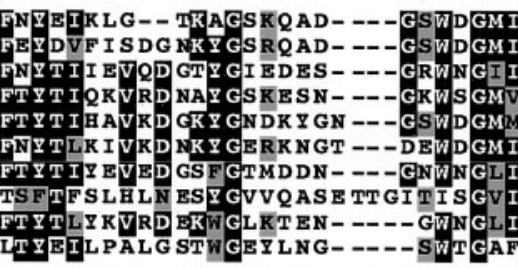

I GELLSGRABA VVA
I GYLLNETADVAVA
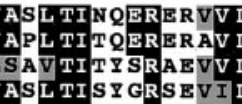

DFSKPFMTTG IS IMIRKP-- DKQEF LQRH EA DL SLSA VTITYSRAEVV DFTLPFMHLG IS I LLARTS E ETDKG

CeGLR- 1

121
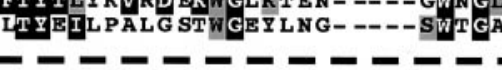

CeGLR-

120

CeGLR-4

CeGLR-3

111

CeGLR- 5

109

.

CeGLR-6 11

CEGLR - 7

CENMR - 2

111

158
142

CegLR-8

117

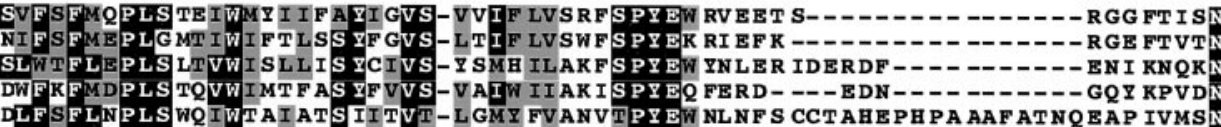

LFR LNPLSWQIWTAIATSIITVT-LGMY FVANVTPY

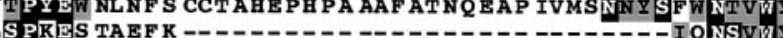
LFKFMKVLE WPVWLCI VAAYLFTS-I LLW IF DRFS PYSF TNNK E R--------- -- - - - YQN DI EKRQFSLK ECLVF MQSFL $Q P L Q S S L W T$ ALF I SVI LVG-LAI Y CLDF KS PFER FY QAD KEMEQDLKK - -- - EF ELW I G KDADENVNFG EAMWF

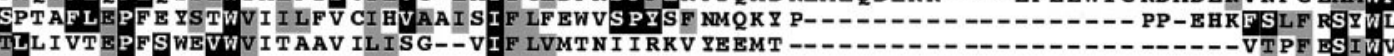

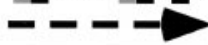

\section{TMI}

TMII

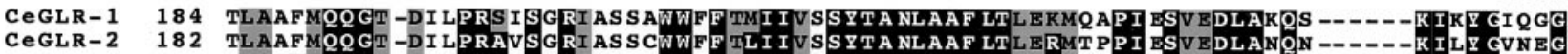
CEGLR-4 179 TMGSLMQQGS-DVIPRAAAT RLI AVVWWMFTQI I ISSYTAQLAAF LTVERMSTPI ESTQDLANQQ ------K IRY GVLKS CEGLR-3 173 TVCSLMQQGS-ZLCPRAASTRLLTGIWWFF ALI LI SSYTA NLAAVLTTRRMETPI BNADDLAAOT ----- -KI KY GTLGR CEGLR-5 196 VLSTMLKGGC-DFGPRAVSTRLLGGTWWVF YLVI I S AYTA NLAAVLTVSRPY IPI KNLDDLANOT -- ----TISY GT IRG

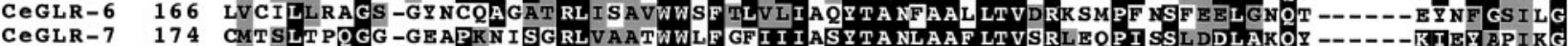

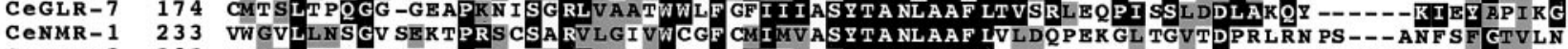

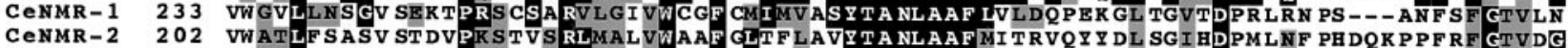
CeGLR-8 169 FFSIFVQQGL-PEQPRSWSCRVLVALWWLASITLSATFTGSLVALFAVDKT NVPF QNIDQLVRLVKQ----GKFEIVMDE

CEGLR-1 257 GSTASFFK-- YSSVQI QQRM WRYMESQVP--

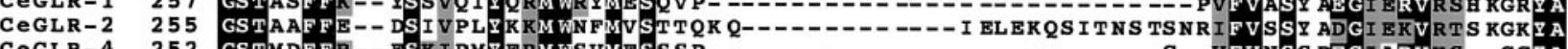
CEGLR-4 252 GSTMDFFR-D ERI PMY ERM WSVMESSSPCEGLR-5 269 GSTMQFFQ-- ESRIAAHVKM WQYMKDK-- CEGLR-6 239 GSTMQFFR-D YSRIETFRRLWERMQSAEPCEGLR-7 247 SASETYFRRMAEIEETFYNM WK EMSLNESM SPRDRAKLAV WDYPV SDKFTNMWRYMQESKLPVNM DTAVDRVLNS VDGFA CENMR-1 310 SNVYQYFK--R--HVELSSMFRKMEPHN-282 GNTHETMKRN WHKMHEYVKH NK Y FRMN-

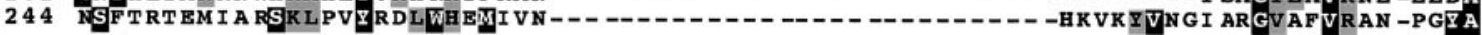

CeGLR-8

$$
\text { - - - - - - - - - }
$$

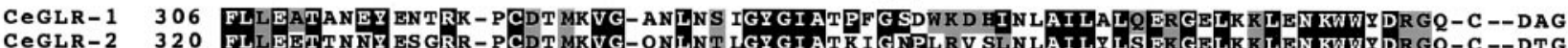

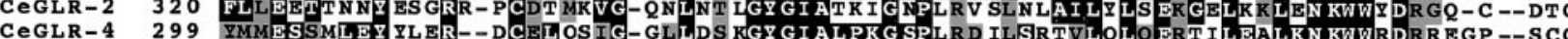

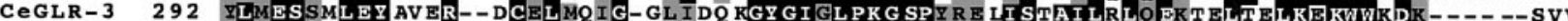
CEGLR-5 314 YLMESTSLEY ETQQ-NCNLTQIG-GVLGS KGYGIALAKR SEWT D FI SROI LLYAKRGI IBMKKTKWWRSKGAACA-STA CEGLR-6 286 FLMESATLDY QVTQ--NCNLTRVGNVVLGS NGYSI ALPKG SKWRE KLTRQI LDLNEKGI I LMLKNIWWKKSQQ--E-CQS CEGLR-7 327 FIGDATEIKYAALT--NCNL QQVG-TEFSR KPYAI AVQSGHILKD KISSAI LMLLNERRLETLKEKWWTDNPN--K-VSC CENMR-1 352 FI DSTRLEF EAAR--BCELRTRG-SLFGR SAYGI GLOKNSPWT P ITSAILRMSESGVMEKLDQ KWIDRGGP----NCV CENMR-2 324 FIY DAVVLDYWAGKDANCAL MTVG-KWASM TGY G I GFPKNSPHT S LVNHYMLOYO OKGDLERLQNFWLTGACT - --P-D

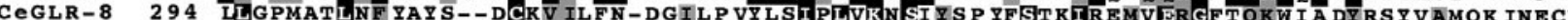
- - - - - - - - - - - - - - - - - - - - - - - - -

CEGLR-1 381 ITVDGSSASLNLSKVAGIFY ILMGGMVISM LAALGE

CEGLR-2 395 TSDGGTSS SLNLSKVAGIFY ILLAGMVLSMCTALVE

CEGLR-4 374 PPPSEKATNSKPQNIFGIFY VLLTGLIVAF LLACGE

CEGLR-3 363 CEQPKRKDOD DGESI GGIFI ILVVGLVLTA VLVIFE

CEGLR-5 390 SAVKHDRF AL SMYNV AGLF I TL GVGI VLAA IVVIFE

CEGLR-6 361 SEPEDLQTAL GAENVYGLFL LLALGSGIGV LCAVLE

CEGLR-7 401 PDSSDESDGI SIQNI GGVFI VILAGIALSI VTLAFE

CENMR-1 425 VEAHKSPARL GLVNMKDIF I LVSSGVALGI FLSFVE

CENMR-2 398 SHSQTQSAPL GI ENFLSAFV LLAGGI IVSV IVLGFE

CEGLR-8 371 STTIGPKSYLDLKRAQGAFW VFLGGAGLGL ALFVGE

$$
\text { - - - TMIV }
$$

Figure 1. Partial sequence alignments of predicted C. elegans ionotropic glutamate receptors. Sequence alignment of a highly conserved region of $\sim 400$ amino acids of GLR-1 and the additional nine putative C. elegans glutamate receptor subunits is shown. This region includes the four hydrophobic domains (TMI-TMIV, solid underline) and two ligand-binding domains (S1, S2, dashed underline with arrows) that are similar in sequence to bacterial amino acid-binding proteins (Nakanishi et al., 1990; Stern-Bach et al., 1994). The polypeptide sequences were derived from partial cDNAs amplified from mixed-stage first-strand cDNA and are numbered on the left beginning with the first amino acid included in the alignment. Identical or similar residues are shaded in black or gray, respectively. Ce, C. elegans. 
$\overline{\text { Table 1. Percentage }(\%) \text { of sequence identity between selected } C \text {. elegans }}$ and rat glutamate receptor subunits

\begin{tabular}{llllll} 
& $\begin{array}{l}\text { Rat } \\
\text { GluR1 }\end{array}$ & $\begin{array}{l}\text { Rat } \\
\text { GluR5 }\end{array}$ & $\begin{array}{l}\text { Rat } \\
\text { Delta1 }\end{array}$ & $\begin{array}{l}\text { Rat } \\
\text { NR1 }\end{array}$ & $\begin{array}{l}\text { Rat } \\
\text { NR2A }\end{array}$ \\
\hline CeGLR-1 & $\mathbf{5 6}$ & 45 & 35 & 33 & 30 \\
CeGLR-2 & $\mathbf{5 3}$ & 45 & 36 & 30 & 28 \\
CeGLR-3 & 44 & $\mathbf{5 1}$ & 35 & 29 & 29 \\
CeGLR-4 & 45 & $\mathbf{4 8}$ & 33 & 27 & 27 \\
CeGLR-5 & 33 & $\mathbf{3 6}$ & 32 & 29 & 26 \\
CeGLR-6 & 39 & $\mathbf{4 0}$ & 30 & 28 & 27 \\
CeGLR-7 & 43 & $\mathbf{4 6}$ & 32 & 28 & 27 \\
CeGLR-8 & 25 & 23 & $\mathbf{2 6}$ & 20 & 22 \\
CeNMR-1 & 24 & 26 & 25 & $\mathbf{4 3}$ & 32 \\
CeNMR-2 & 27 & 27 & 27 & 32 & $\mathbf{4 0}$
\end{tabular}

Pairwise amino acid identities were calculated using the ALIGN optimal global alignment program (see Materials and Methods).

GLR-1 and GLR-5; AVD expressed GLR-1, GLR-2, and GLR-5; RIM expressed GLR-1, GLR-4, and GLR-5; and RIF expressed GLR-4 and GLR-5. Presumably, these neurons could create a variety of mature heteromeric receptors from these subunits. Third, some neurons expressed only one subunit. For example, RIB expressed only GLR-4, LUA expressed GLR-5, and AIA expressed GLR-2. Whether these subunits can form functional homomeric receptors or whether other subunits were expressed at levels too low to detect remains to be determined.

Although most glutamate receptor subtypes are expressed in multiple neurons, two non-NMDA subunits, GLR-3 and GLR-6, were exclusively expressed in the thermosensory interneuron RIA (Fig. 6). This neuron also expressed the GLR-2 receptor subunit (Fig. 5). RIA is considered the major integrative thermosensory interneuron because it receives input from the interneurons AIY and AIZ. In addition, as revealed by laser ablation studies, it is required for worms to thermotax in defined temperature gradients (Mori and Ohshima, 1995).

\section{Two genes, $g / r-7$ and $g / r-8$, were primarily expressed in the pharyngeal nervous system}

The pharynx of $C$. elegans functions to ingest and process food. It contains 58 cells, including 20 neurons that comprise the pharyngeal nervous system. This collection of neurons is almost entirely separate and independent from the rest of the $C$. elegans nervous system (Albertson and Thomson, 1976). The function of some of these neurons is known to modulate pharyngeal pumping (Raizen and Avery, 1994). Two subunits, GLR-7 and GLR-8, were expressed in the pharyngeal nervous system (Fig. 7). GLR-8 is expressed in all GLR-7-expressing neurons but is also found uniquely expressed in other pharyngeal and extrapharyngeal neurons (Fig. 7, Table 2). Both GLR-7 and GLR-8 are outliers in the sequence alignment, and GLR-8 cannot be obviously categorized into NMDA or non-NMDA classes (Fig. 3). However, coexpression of GLR-7 and GLR-8 in specific neurons suggests that they may encode subunits of the same subtype and combine to form glutamate-gated receptors.

\section{Expression of all glutamate receptor subunits began during embryogenesis}

Expression of the GFP reporter constructs could be observed at all larval stages and in the adult. The onset of expression was typically noted in late embryogenesis (Fig. 8). glr-5 had the earliest onset of expression in which GFP fluorescence could be observed at the twofold stage ( $\sim 450$ min after fertilization). Within another $100 \mathrm{~min}$ of development (at the threefold stage), expression of $g l r-1, g l r-2, g l r-4, g l r-7, g l r-8, n m r-1$, and $n m r-2$ was first observed. We could not detect $g l r-3$ or $g l r-6$ expression until near hatching. However, the GFP signal from the transgenic strains that expressed these constructs was rather weak, and the late onset of expression may simply reflect low expression levels.

\section{Expression of GLR-4 and GLR-5 was dependent on the homeodomain protein UNC-42}

The genetic control of glutamate receptor expression is not well understood. In a recent study, the homeodomain gene $u n c-42$ was found to be required for the development of neuronal identity and specifically required for the expression of GLR-1 in the AVA, AVD, and AVE interneurons and the RMD motor neurons (Baran et al., 1999). UNC-42 itself was expressed in many additional neurons that were not known to express glutamate receptors. To determine whether unc-42 differentially regulates glutamate receptor expression, we examined the expression pattern of glutamate receptor subunits in an $u n c-42$ mutant background. We confirmed that $u n c-42$ is required for GLR-1 expression in AVA, AVD, AVE, and RMD neurons (Fig. 9A). Of the other genes encoding glutamate receptor subunits, only $g l r-4:: G F P$ and $g l r-5:: G F P$ had altered GFP expression. GLR-4 and GLR-5 were normally expressed in many neurons; however, the expression of GLR-4 in AVA and RMD (Fig. 9B) and the expression of GLR-5 in AVA, AVD, AVE, and RMD (Fig. 9C) were dependent on unc-42. Interestingly, expression of GLR-2 and the two NMDA subunits NMR-1 and NMR-2 was independent of unc-42. These subunits were also expressed in AVA, AVD, AVE (GLR-2, NMR-1, and NMR-2), and a subset of the RMD neurons (GLR2). Thus, of the neurons that expressed glutamate receptor subunits and whose identity was controlled, in part, by unc-42, the expression of a subset of non-NMDA receptor subunits was dependent on unc-42. The glutamate receptor subunits GLR-3, GLR-6, GLR-7, and GLR-8 were expressed in neurons that did not express $u n c-42$, and their expression was not found to be dependent on $u n c-42$.

\section{unc-42 regulates axon outgrowth in a subset of the command interneurons}

The command interneurons have been divided into two interconnected subclasses, those that primarily regulate backward movement (AVA, AVD, and AVE) and those that primarily regulate forward movement (AVB and PVC) (Chalfie et al., 1985) (Fig. $10 H)$. Whether moving forward or backward, unc-42 mutants move slowly and haltingly and often display kinking behavior. They also have abnormalities in the escape response to tactile stimulation (Baran et al., 1999) (Table 3). Rather than moving backward in response to anterior stimulation (Chalfie et al., 1985), unc-42 mutants either fail to respond or move forward (Table 4). The backing response to tactile stimulation of the nose is also disrupted in unc-42 mutants (Baran et al., 1999) (Table 4). The normal response to posterior tactile stimulation is forward movement, and this response, although diminished and uncoordinated, still occurs in unc-42 mutants. How can these various defects be explained?

Because $n m r-1:: G F P$ expression was not dependent on $u n c-42$, we were able to use this transgene to study the morphology of the command interneurons in unc-42 mutants. Transgenic unc-42 mutants showed severe axon outgrowth defects in the backward command interneurons AVA, AVD, and AVE (Fig. 10). Nor- 
RatDelta 1 RatDelta2 RatGluR2 RatgluR4 RatGluR 1 RatGluR3 CEGLR-1

CEGLR-2 DrOGIUR1 RatGluR5 RatGluR6 RatGluR7 RatKA 1 RatKA 2 CeGLR-4 CEGLR-3 RatNR1 D IONR 1 CENMR- 1 RatNR2A RatNR2B RatNR2C RatNR2D CENMR-2 DrOGIUR2 CeGLR- 6 CeGLR- 5 CeGLR- 7 RatNR3 A CEGLR- 8

RatDelta 1 RatDelta2 RatGluR2 RatGluR4 RatGluR 1 RatgluR3 CeGLR-1 CeGLR-2 DrOGluR 1 RatGluR5 RatgluR6 RatGluR7 RatKA 1 RatKA 2 CeGLR-4 CeGLR-3 RatNR1 D rONR 1 CeNMR-1 RatNR2A Rat NR2 B RatNR2C RatNR2D CeNMR- 2 DrOGluR2 CeGLR- 6 CeGLR- 5 CeGLR- 7 RatNR3 A CeGLR- 8

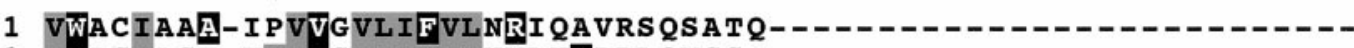

1 LWACIAGT-VLLVGLLVYLLNWLNPPRLQMGS--

1 IWMCIVFA-YI GVSVVLFLVSRFS P Y EWHTEEFEDGRETQSS -

1 IWMCIVFA-YIGVSVVLFLVSRFSPYEWHTEEPEDGKEGPSD--

1 IWMCI VFA-YI GVSVVLFLVSRFS P Y EWHSEEFEEGRDQTTS--

1 IWMCI VFA-YI GVSVVLFLVSRFS P Y EWHLEDNNEEPRDPQS P-

1 IWMY I IFA-YI GVSVVIFLVSRFS P Y EWRVEETS--0- RGG--

1 IWIFTLSS-YFGVSLTIFLVSWFSPYEKRIEFK-----RGE--

1 IWISVILS-YVGVSFVLYFVTRFPPYEWRIVRRPQADSTAQQPPGIIGGATLSEPQAHVP

1 IWMY VLLA-CLGVSCVLFVIARFTPYEWYNPHPCNPD--

1 IWMY VLLA-CLGVSCVLFVIARFS P Y EWY NP H PCNPD--

1 IWMY VLLA-YLGVSCVLFVIARFS PY EWY DA H PCNPG---

1 VWLFMLLA-YLAVS CVLFLVARLTP Y EWY S P PCAQGR

1 VWLFMLLA- YLAVSCVLFLAARLS P Y EWY NPH PCLRAR--

1 VWISLLIS-YCIVSYSMHILAKFS PYEWYNLERID-E--

1 VWIMTFAS-YF VVSVAIWIIAKIS PYEQFERD--0-0-0-0-0-0-0-EDNGQY

1 LWLLVGLS-VHVVA VMIYLLDRFS PFGRFKVNSEEE-_-

1 LWIL VMVS - VH VVAL VLYLLDRFS PFGRF KLSHS DSN--

1 LWTALFIS-VILVGLAI Y CLDFKS PFERFYQADKEMEQDLKKE----------FELWIG

1 VWVMMF VMLLI VSAIAVFVFE YFS PVGYNRNLAKGKAP

1 VWVMMF VMLLI VSA VAVFVFE YFS PVGYNRCLADGREP-_-

1 VWVMMF VMCLTVVAITVFMFE YFS PVS Y NQNLTKGKKP

1 VWVMMF VMCLT VVA VTVFIFE YLS PVGYNRSLATGKRP

1 TWVI ILFVCIHVAAISIFLFEWVS PYS FNMQKY P-P-_-

1 VWI YMIFA-QLIMTLAFVFIARLSYREWL P PNPA I QD P-_-

1 VWTFSAIA-TVITALLVTVAAVLS PKESTAEFK-

1 IWTAIATS-IITVTLGMYFVANVTPYEWNLNFSCCTAHEPHPAAAFATN----- QEAP

1 VWLCIVAA-YLFTSILLWIFDRFS PYSFTNNKERYQN-

1 MWLGIFVA-LHITAIFLTLYEWKS PFGMTPKGRN-------

1 VWVITAAVILISGVIFLVMTNIIRKVYEEMTTMI

33 PRPSASATLHSAIWIVYGAFVQQGGES-SVNSVAMRIVMGSWWLFTLIVCSSYTANLAAF 32 - - MTSTTL YNSMWFVYGSFVQQGGEV-PYTTLA TRMMMGAWWLFALI VISS Y TANLAAF 42 -ESTNEFGIFNSLWFSLGAFMRQGCDI-SPRSLSGRIVGGVWWFFTLIIISS T ANLAAF 42 - QP PNEFGIFNSLWFSLGAFMQQGCDI-SPRSLSGRIVGGVWWF FTLI I ISS Y TANLAAF 42 -DQSNEFGIFNSLWFSLGAFMQQGCDI-SPRSLSGRIVGGVWWFFTLI I ISSYTANLAAF 43 PDPPNEFGIFNSLWFSLGAFMQQGCDI-SPRSLSGRIVGGVWWFFTLI I ISS YTANLAAF 37 FTISNDFS VYNCLWFTLAAFMOQGTDI-LPRSISGRIASSAWWF FTMI IVSS Y TANLAAF 36 FTVTNEFTL YNSLWFTLAAFMOQGTDI-LPRAVSGRIASS CWWFFTLI IVS Y TANLAAF 60 PVPPNEFTMLNSFWY SLAAFMQQGCDI-TPPSIAGRIAAAVWWF FTIIIISS Y TANLAAF 38 DVVENNFTLLNSFWFGVGALMOQGSEL-MPKALSTRIVGGIWWFFTLIIISS Y ANLAAF 38 DVVENNFTLLNSFWFGVGALMROGSEL-MPKALSTRIVGGIWWFFTLIIISSYTANLAAF 38 EVVENNFTLLNSFWFGMGSLMOQGSEL-MPKALSTRIIGGIWWFFTLIIISSYTANLAAF 39 NLLVNQYSLGNSLWF PVGGFMOQGSTI-APRALSTRCVS GVWWAFTLI I ISS YTANLAAF 39 HILENQYTLGNSLWFPVGGFMQQGSEI-MPRALSTRCVSGVWWAFTLI I ISSYTANLAAF 42 KNQKNQFTVLNSFWFTMGSLMQQGSDV-IPRAAATRLI AVVWWMFTQI I I S Y TAQLAAF 38 K PVDNQFSLRNSFWFTVCSLMQQGSEL-CPRAASTRLLTGIWWFFALIIISS YTANLAAV 36 - EEDALTLSSAMWF SWGVLLNSGI GEGAPRS FSARIL GMVWAGFAMI IVAS Y TANLAAF 37 - EEKALNLSSA VWFAWGVLLNSGIGEGTPRS FSARVLGMVWAGFAMI IVAS YTANLAAF 49 KDADENVNFGEAMW FVWGVLLNSGVSEKTPRSCSARVLGIVWCGFCMIMVAS YTANLAAF 39 - -TGLLFTIGKA IWLLWGLVFNNSVPVQNPKGTTSKIMVSVWAFFAVIFLAS Y TANLAAF 39 - -GGPSFTIGKA IWLLWGLVFNNS VPVQNPKGTTSKIMVSVWAF FAVIFLAS Y TANLAAF 39 - -GGPSFTIGKSVWLLWALVFNNS VPIENPRGTTSKIMVLVWAF FAVIFLAS YTANLAAF 39 --GGSTFTIGKSIWLLWALVFNNS VPVENPRGTTS KIMVLVWAF FAVIFLAS YTANLAAF 36 - - PEHKF S FRS YWLVWATLF SAS VSTDVPKSTVSRLMALVWAAFGLTFLAVYTANLAAF 38 DELENI WNVNNSTWLMVGS IMQQGCDI-LPRG PHMRILTSMWWF FALMMLST T ANLAFL 33 - - - - I QNSVWYLVCILLRAGSGY - NCQAGATRLISAVWWSFTLVLIA QY TANFAAL 53 I VMSNNYSFWNTVWYVLSTMLKGGCDF-GPRA VSTRLLGGTWWVFYLVI I SAYTANLAAV 37 DIEKRQFSLKECLWFCMTSLTPQGGGE-APKNISGRLVAATWWLFGFI I I AS Y TANLAAF 34 - -RNKVFSFSSALNVCYALLFGRTAAIKPPKCWTGRFLMNLWAIFCMFCLSTYTANLAAV 32 -----VTPFESIWVFFS I FVQQGL PE-QPRSWSCRVLVALWWLAS I TLSA T FTGSLVAL

Figure 2. Comparison of C. elegans, Drosophila, and rat ionotropic glutamate receptor subunits. Sequence alignment of C. elegans, Drosophila, and rat ionotropic glutamate receptor subunits beginning immediately at TMI and terminating at TMIII is shown. C. elegans subunits have signature features found in both vertebrate and invertebrate subunits. These include predicted hydrophobic domains (solid underline), a conserved glutamine residue in TMII ( filled circle; a target of RNA editing in a subset of vertebrate non-NMDA subunits), and a sequence of nine amino acids in TMIII (dashed line) found in almost all known ionotropic glutamate receptor subunits. This region also contains a conserved alanine residue (filled triangle) that when mutated to threonine causes the ion channel to be constitutively open (Zuo et al., 1997; Zheng et al., 1999). Amino acids are numbered on the left beginning with the first residue in TMI. Identical or similar residues are shaded in black or gray, respectively. Dro, Drosophila. 


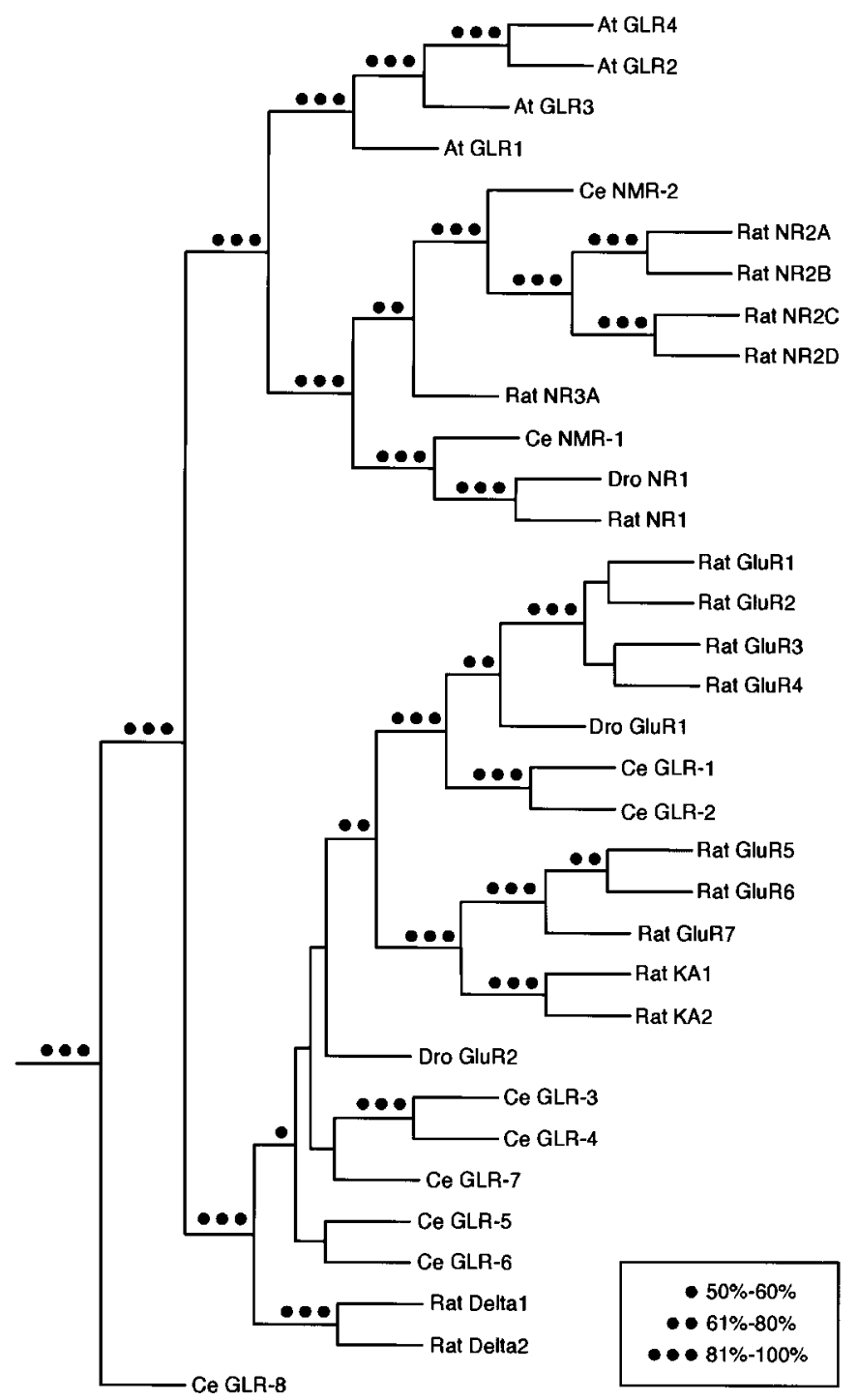

Figure 3. Phylogenetic tree of the amino acid sequences for glutamate receptor subunits. Unrooted phylogenetic tree of the amino acid sequences for the 10 identified $C$. elegans putative glutamate receptor subunits and selected rat, Drosophila, and Arabidopsis subunits (see Materials and Methods) is shown. The predicted C. elegans polypeptides are based on the cloned partial cDNAs (Fig. 1). The schematic shows clusters of relationships between the amino acid alignments of the glutamate receptor subtypes. The total length of the horizontal lines between different receptors is proportional to the difference between sequences; distance along the vertical axis has no significance. Five hundred bootstrap replicates were performed, and the bootstrap values are indicated by dots on the supporting branches. No dot indicates a value $<50 \%$. At, $A$. thaliana.

mally, the processes of these neurons enter the nerve ring and then travel posteriorly in the ventral cord (Fig. 10F) (White et al., 1986). However, in unc-42 mutants, the processes of these neurons extended anteriorly, laterally, or dorsally, and in many of these worms multiple displaced processes were evident (Table 4; Fig. 10A-D). Although it was difficult to identify the origin of each aberrant process, the processes of AVD were disrupted in most worms. Furthermore, because the migration of some processes terminated prematurely, fewer than the expected number of processes were observed in the ventral cord (Fig. 10G). This suggests that the aberrant processes reflect misdirection of the

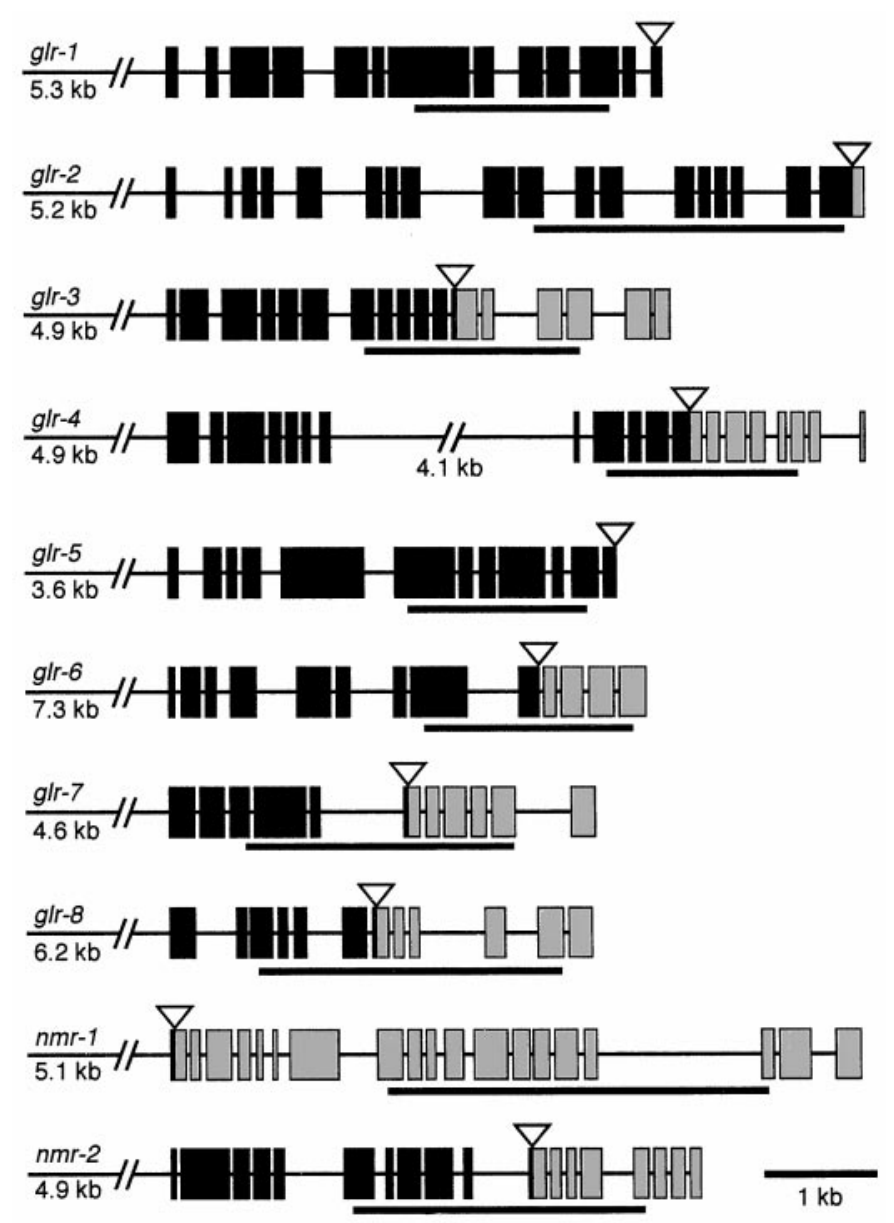

Figure 4. Glutamate receptor-GFP fusion proteins. Schematic representation of the genomic fusions to GFP for each of the glutamate receptor subunits. Boxes represent exons, and horizontal lines between boxes represent introns. Black and gray boxes represent genomic sequence that was either included or omitted from the GFP fusion construct, respectively. The underlined regions represent intron and exon boundaries that have been confirmed by cDNA sequence that was used to predict the amino acid sequence shown in Figures 1 and 2. The amount of upstream regulatory sequence included in each fusion is indicated as is the site of GFP fusion (inverted triangle).

primary wild-type process rather than additional ectopic projections. In contrast to the processes of AVD, the processes of PVC, a forward command interneuron that does not express UNC-42, never appeared disrupted (data not shown). The unc-42 axon outgrowth defects were completely rescued in transgenic worms that expressed a wild-type genomic clone encoding UNC-42 (Table 4; Fig. 10E). These axonal defects may depend solely on the lack of UNC-42 expression in the affected neurons, or it may be dependent on expression of UNC-42 in neighboring neurons or cells. The rescue of the axon outgrowth defects observed in AVA, AVD, and AVE was accompanied by rescue of the movement and touch-response abnormalities. unc-42 mutants that expressed the wild-type unc-42 transgene had normal forward and backward movement, and touch sensitivity and escape responses to nose touch, anterior touch, and posterior touch were comparable with that of wild-type worms (Table 4).

\section{DISCUSSION}

A detailed analysis of how individual receptor subunits influence synaptic transmission and contribute to neuronal processing and 

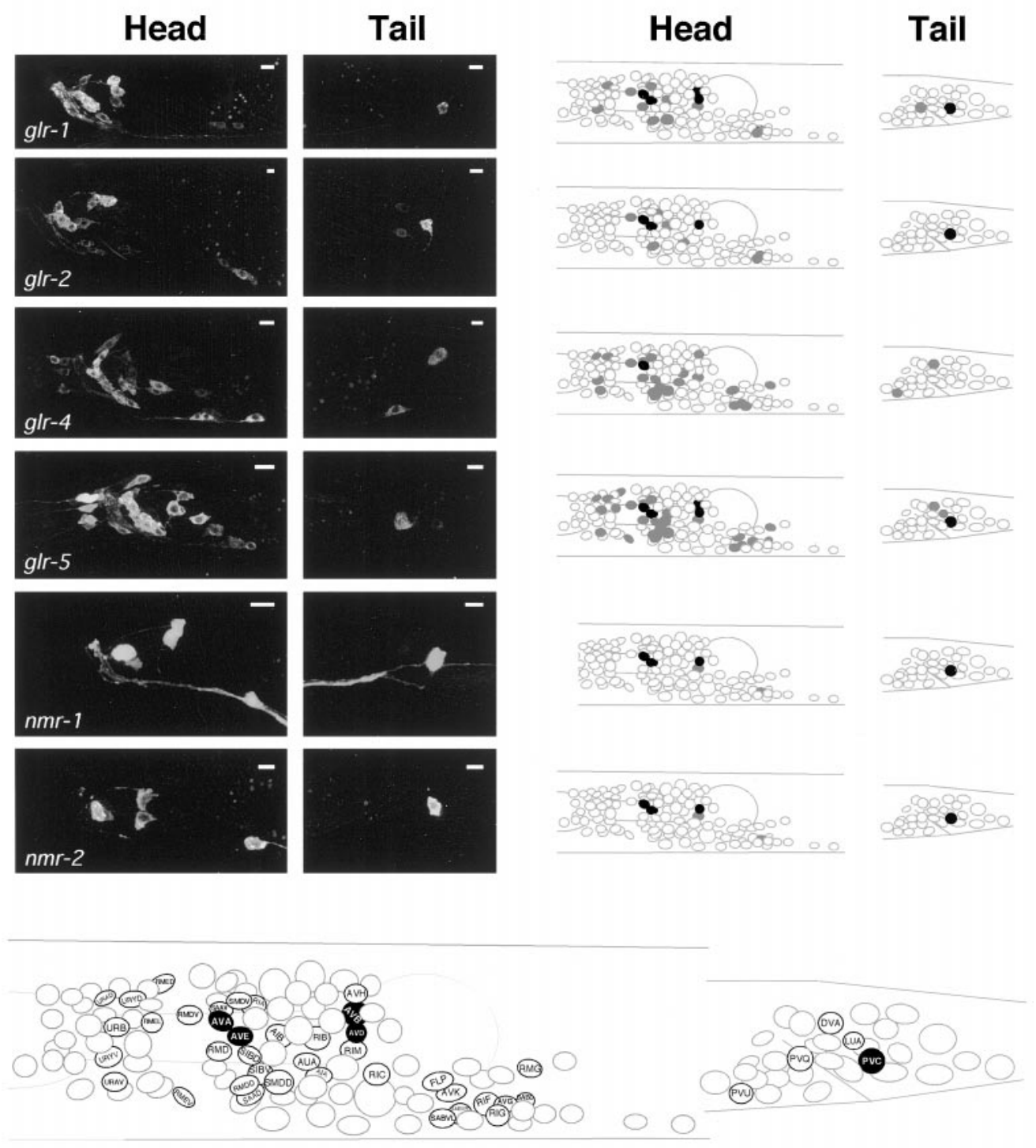

Figure 5. Four non-NMDA and two NMDA ionotropic glutamate receptor subunits are expressed in the command interneurons of the locomotory control circuit. Confocal micrographs of transgenic worms expressing GFP fusions to $g l r-1, g l r-2, g l r-4, g l r-5, n m r-1$, and $n m r-2$ are shown. Only the anterior head and posterior tail regions of the worm are shown (two left columns). A schematic reconstruction of the neuronal cell bodies in the head and tail of the worm are also shown [two right columns; adapted from White et al. (1986)]. Cells filled in gray and black represent neurons that express the respective subunit. Each of these GFP fusions is expressed in at least one of the five pairs of command interneurons, AVA, AVB, AVD, AVE, and PVC (black cells). Neurons that express at least one of the six receptor subunits have been labeled in the bottom panel. The command interneurons of the locomotory control circuit are filled in black. Scale bars, $5 \mu \mathrm{m}$.

behavior is difficult in the vertebrate nervous system because of its complexity. We have begun to address these questions by undertaking a comprehensive analysis of the distribution of glutamate receptors in the relatively simple nervous system of $C$. elegans. This analysis is a first step toward identifying the various combinations of subunits that interact to form ion channels and determining the specific contribution of these channels to worm behavior. In the $C$. elegans nervous system, individual neurons can be identified, receptor expression can be modified, and neuronal function can be studied in parallel with behavioral analysis.

\section{Neuronal expression of glutamate receptors in C. elegans}

In the vertebrate nervous system, 18 different receptor subunits, as well as alternatively spliced or RNA-edited variants, are differentially expressed throughout the CNS (Petralia and
Wenthold, 1996; Hollmann, 1999). Individual subunits may be widely distributed (NR1, NR2A, and GluR2), have a more limited tissue distribution (GluR4 and NR2C), have lower levels of expression (kainate receptors), or have a distribution that is limited to only a few cell types (delta2 receptor). Individual neurons often express many different receptor subunits, including AMPA, kainate, and NMDA subtypes that may be intermingled at synapses (Takumi et al., 1999a). In addition, in some neurons subunits are found to be differentially localized to distinct synapses (Landsend et al., 1997; Rubio and Wenthold, 1997).

In $C$. elegans, our cloning and expression studies revealed a surprising number of putative glutamate receptor subunits for an organism with only 302 neurons. By comparing the amino acid sequence of these subunits with known vertebrate receptor subunits, we have assigned subunits to NMDA and non-NMDA 


\begin{tabular}{|c|c|c|}
\hline Gene & Cosmid & Expression pattern \\
\hline glr-1; III & C06E1 & AVA, AVB, AVD, AVE, PVC, AIB, RMD, RIM, SMD, AVG, PVQ, URY \\
\hline$g l r-2 ;$ III & B0280/K04G7 & AVA, AVD, AVE, PVC, RMDV, RMDD, AIA, AIB, AVG, RIG, RIA, M1 pharynx, RIR(?) \\
\hline$g l r-3 ; \mathrm{I}$ & F22D6/K10D3 & Only one neuron, RIA \\
\hline glr-4; II & C06A8 & $\begin{array}{l}\text { AVA (faint), RMD (all), SMD (all), SAA (all), SIB (all), RIB, RIM, AVH, FLP, RMG, DVA, AUA, } \\
\text { PVD, URY, URA, SAB, RIF, DB in ventral cord(?), PVU(?) }\end{array}$ \\
\hline$g l r-5 ; \mathrm{V}$ & ZC196 & $\begin{array}{l}\text { AVA, AVB, AVD, AVE, PVC (?); RIM, RIC, RMD (all), SMD (all), SIB (all), RME (all), AVK, RMG, } \\
\text { SABVL, SABVR, SABD, RIF, VC, LUA, PVQ, URB, URY, URA(?), DVA(?), AIB(?), HSN(?) }\end{array}$ \\
\hline$g l r-6 ; \mathrm{X}$ & $\mathrm{C} 53 \mathrm{~B} 7 / \mathrm{F} 41 \mathrm{~B} 4$ & Only one neuron, RIA \\
\hline$g l r-7 ; \mathrm{X}$ & C43H6/T07D1 & I3, I2, I6, MI, NSM, I1(?). \\
\hline$g l r-8 ; \mathrm{X}$ & $\mathrm{C} 15 \mathrm{~B} 12 / \mathrm{F} 22 \mathrm{~A} 3$ & I1, I2, MC, NSM, M3 (left/right), I3, MI M4, M3 (left/right), I6, M5, BDU, ALM, PLM, URB (left/right) \\
\hline$n m r-1 ; \mathrm{II}$ & F07F6/F56D1 & AVA, AVD, AVE, RIM, AVG, PVC \\
\hline$n m r-2 ; \mathrm{V}$ & T01C3/F14H8 & AVA, AVD, AVE, RIM, AVG, PVC \\
\hline
\end{tabular}

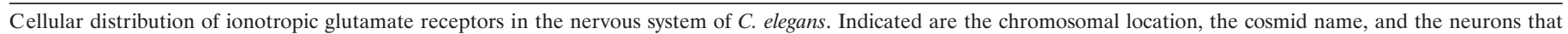
show reproducible GFP expression. (?) indicates uncertainty about neuronal identity because of weak or variable GFP expression.
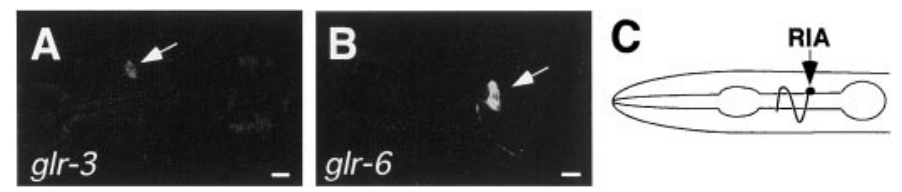

Figure 6. Two ionotropic glutamate receptor subunits are exclusively coexpressed in the thermoregulatory interneuron RIA (arrows). $A, B$, Confocal micrographs (anterior region only) of transgenic worms expressing $g l r-3:: G F P(A)$ and $g l r-6:: G F P(B)$ are shown. $C$, Expression of both fusion proteins is detected in a single neuron, the thermoregulatory interneuron RIA (arrow). Scale bars, $5 \mu \mathrm{m}$.

classes. However, whether receptors formed from these subunits are characteristically activated by the selective pharmacological agents AMPA, kainate, and NMDA remains to be determined. The receptor subunits were predominantly expressed in interneurons, and most neurons expressed a number of receptor subunits. Subunits closely related by sequence were likely to be coexpressed in the same neurons, e.g., GLR-1 and GLR-2 or NMR-1 and NMR-2. However, some neurons expressed only one subunit, which might therefore form functional homomeric receptors. Alternatively, we have not identified all of the ionotropic glutamate receptor subunits in C. elegans (see Materials and Methods for additional candidate glutamate receptors). In contrast, other neurons, such as AVA, expressed six receptor subunits. Interestingly, unlike vertebrate neurons, most $C$. elegans neurons do not express NMDA receptors. Consequently, the majority of neurons that express non-NMDA receptor subtypes do not express either of the NMDA subtypes NMR-1 or NMR-2. Unlike the case for vertebrate glutamate receptor subunits, we found no evidence of alternative splicing or RNA editing of any subunits. In Drosophila, neuromuscular transmission is glutamatergic; however, in C. elegans, glutamate receptor expression in muscle cells was not observed.

The subunit composition of vertebrate glutamatergic synapses changes with activity. Whether the initial formation of glutamatergic synapses is also dependent on activity is unclear. One model suggests that glutamatergic synapses initially contain only NMDA receptors and that non-NMDA receptors are later recruited to the synapse in an NMDA receptor and activitydependent process. Thus, synaptic plasticity is achieved by modulating the relative level of non-NMDA receptor expression in response to patterns of synaptic activity. In this view, the expres-
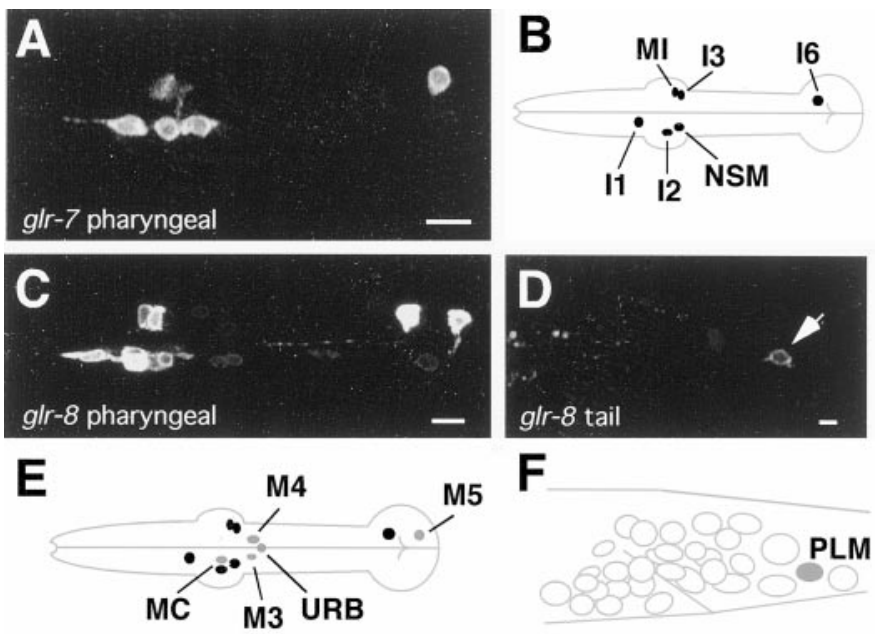

Figure 7. Two ionotropic glutamate receptors are coexpressed in the pharyngeal nervous system. $A$, Confocal image of a transgenic worm expressing the $g l r-7:: G F P$ transgene in the pharyngeal nervous system (head region only). $B$, Diagram of the pharynx and the neuronal cell bodies that express $g l r-7: \because G F P$. $C, D$, Confocal images of a transgenic worm expressing $g l r-8:: G F P$ in the pharyngeal nervous system $(C$, head region only) and in a single neuron in the tail (arrow; $D)$. $E, F$, Neuronal cell bodies that express glr-8::GFP. Neurons filled in black coexpress glr-7::GFP and $g l r-8:: G F P$. Neurons filled in gray only express $g l r-8:: G F P$ in either the pharyngeal nervous system $(E$; URB is the only neuron of this subset that is not considered part of the pharyngeal nervous system) or the tail $(F)$. Scale bars, $5 \mu \mathrm{m}$.

sion of glutamate receptors at synapses is a dynamic process and is partly dependent on the activation of NMDA receptors. Thus, in hippocampal CA1 pyramidal neurons, certain synapses, termed "silent synapses," contain only NMDA receptors (Liao et al., 1995). During development or with activity that leads to the activation of NMDA receptors, these synapses acquire AMPA receptors and become more active (Petralia et al., 1999a; Shi et al., 1999; Takumi et al., 1999b). However, there is also strong evidence that AMPA-mediated synaptic neurotransmission develops in the absence of NMDA receptor activity (O'Brien et al., 1997; Rao and Craig, 1997; Gomperts et al., 2000). In C. elegans, synapse formation in most neurons must be independent of NMDA receptor activity, because we have shown that most neurons that express non-NMDA receptors do not express NMDA receptors. Thus, for these neurons, synapse formation 


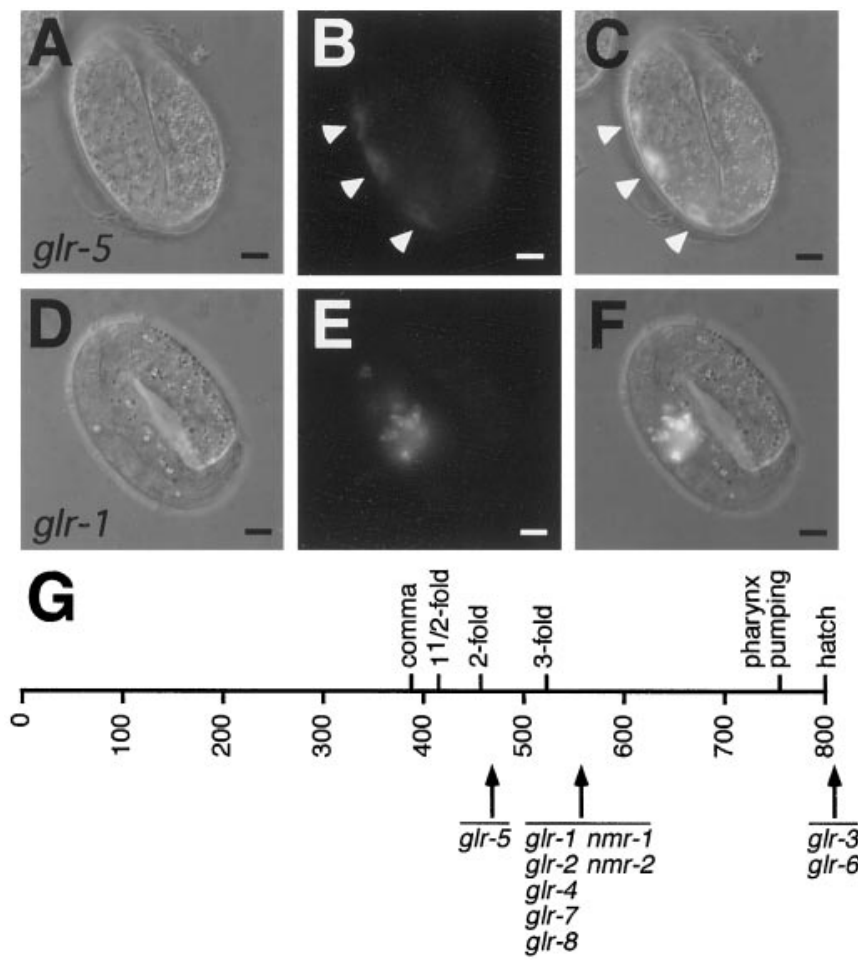

Figure 8. Expression of ionotropic glutamate receptor subunits can be detected during embryogenesis. $A-C$, Image of a twofold stage embryo that expressed glr-5::GFP (arrowheads). Expression of this fusion protein was detected the earliest of all of the GFP fusion transgenes. $D-F$, Image of a threefold stage embryo that expressed $g l r-1:: G F P$. Most of the GFP fusions were first detected at this stage. $G$, Time course of embryogenesis (minutes) indicating the approximate time of the earliest detected expression of each of the receptor subunits. $g l r-3:: G F P$ and $g l r-6:: G F P$ expression was not detected during embryogenesis. $A, D$, Nomarski. $B, E$, FITC. $C$, $F$, Overlay. Scale bars, $5 \mu \mathrm{m}$.

and function are independent of NMDA receptor activity. Whether the command interneurons that coexpress NMDA and non-NMDA receptor subunits show activity dependence of synapse formation remains to be determined.

What are the functions of $C$. elegans glutamate receptor subunits? How might they contribute to neuronal processing in the worm? Hints are provided by their respective neuronal expression patterns. Thus, GLR-3 and GLR-6 were expressed in an interneuron required for thermotaxis and may be required for normal thermotaxis behavior; GLR-7 and GLR-8 were expressed in the pharyngeal nervous system and may participate in pharyngeal function; and GLR-1, GLR-2, GLR-4, GLR-5, NMR-1, and NMR-2 were expressed in command interneurons and may contribute to locomotory control. The large number of subunits in some neurons suggests that considerable receptor diversity may exist. However, which subunits form functional glutamate-gated channels remains to be determined.

\section{How many neurons are glutamatergic?}

The widespread expression of glutamate receptors in interneurons and motor neurons suggests that many sensory neurons and interneurons are glutamatergic. A recent study identified EAT-4 as a putative $\mathrm{Na}-\mathrm{P}_{\mathrm{i}}$ cotransporter in C. elegans that is required for vesicular uptake of glutamate (Lee et al., 1999). Furthermore, the mammalian homolog of EAT-4 has now been identified and functions to transport glutamate into synaptic vesicles (Bellocchio et al., 2000; Takamori et al., 2000). The EAT-4 cotransporter is expressed in at least 15 different classes of neurons in C. elegans. On the basis of the expression patterns of EAT-4 (Lee et al., 1999), the various glutamate receptors described here, and the serial electron microscopic analysis of the C. elegans nervous system (White et al., 1986), one can begin to predict which synaptic inputs are glutamatergic. For example, AVA expresses a variety of glutamate receptors and receives synaptic inputs from a large number of neurons. These inputs make contact in different regions of the AVA process. However, only a small subset of these input neurons express EAT-4 (Lee et al., 1999). Thus, the potentially glutamatergic neurons include ASH, AUA, and FLP in the nerve ring, PVD and PLM in the ventral cord, and LUA in the preanal ganglion. These predictions can be directly tested. For example, by the use of GFP-tagged presynaptic and postsynaptic markers, GLR-1 has been shown recently to colocalize with a subset of ASH presynaptic specializations (Rongo et al., 1998). Interestingly, the number of GLR-1 synapses (320) reported by Rongo et al. differs markedly from that predicted by counting the synaptic inputs provided by EAT-4-expressing neurons $(\sim 130)$. This discrepancy can be explained if low, undetected levels of EAT-4 were expressed in additional neurons. Alternatively, other unidentified transporters may participate in vesicular uptake of glutamate.

\section{Expression of glutamate receptor subunits is differentially regulated by UNC-42}

Mutations that affect the connections among the locomotory command interneurons should disrupt locomotion. For example, $v a b-8$ mutants are uncoordinated and have particular difficulty moving backward. In these mutants the outgrowth of most posteriorly directed axons, including the axons of a subset of the command interneurons, is disrupted (Wightman et al., 1996). Interestingly, unc-42 mutants are also severely uncoordinated and do not move forward or backward in a normal manner. They are sensitive to body wall touch, but rather than moving backward in response to anterior tactile stimulation, they usually move forward. We have shown that unc-42, required for the expression of GLR-1 in the backward command interneurons (AVA, AVD, and AVE) (Baran et al., 1999), is also required for GLR-4 and GLR-5 expression in these neurons. Defective expression of GLR-1 in unc-42 mutants does not cause the uncoordinated locomotion because $g l r-1$ mutants move in a coordinated manner. Because unc-42 mutants are also defective in the expression of GLR-4 and GLR-5, it may be that compound loss of all three subunits leads to the severe locomotory defects observed in unc-42 mutants. Loss of single subunits, such as GLR-1, may be compensated by the presence of the remaining subunits. However, because unc-42 mutants show multiple defects, the phenotype is unlikely to be caused by loss of glutamate receptors alone.

\section{UNC-42 is required for axon outgrowth of the backward command interneurons}

By using the $n m r-1$ promoter to express GFP in AVA, AVD, and AVE in unc-42 mutants, we have shown that the most likely cause of uncoordinated movement in unc-42 mutants was disruption of synaptic communication secondary to defective axon outgrowth of AVA, AVD, and AVE. Whether these axon outgrowth defects were secondary to defects in glutamate receptors, defects in the expression of additional gene products in interneurons, or defects in the target tissues remains to be determined. Our results suggest that the sensory defects (nose touch and body touch) may also be caused by disruption of the interneuronal circuitry. When these 
Figure 9. UNC-42 is required for expression of GLR-1, GLR-4, and GLR-5. $A-C$, Confocal images of unc42(e270) transgenic worms that expressed $g l r-1: \because G F P(A)$, $g l r-4:: G F P(B)$, and $g l r-5:: G F P(C) . D-F$, Diagram of neuronal cell bodies that express $g l r-1(D), g l r-4(E)$, and $g l r-5$ $(F)$. Cell bodies filled in gray and black represent those that expressed the respective subunits in wild-type worms. Cell bodies filled in gray represent those that no longer express the subunits in unc-42 mutants. unc- 42 is required for $g l r-1$ expression in the command interneurons AVA, AVD, and AVE and in the RMD motor neurons (Baran et al., 1999). It is also required for $g l r-4$ and $g l r-5$ expression in these same cells. Scale bars, $5 \mu \mathrm{m}$.

Figure 10. unc-42 disrupts the axon outgrowth of AVA, AVD, and AVE. $A-D$, Confocal images of transgenic unc-42(e419) mutants $(A, B)$ and unc-42(e270) mutants $(C, D)$ that expressed the $n m r-1:: G F P$ transgene. Abnormal processes can be observed extending anterior to the nerve ring (arrows) or along dorsal or lateral paths (arrowheads). E, Confocal image of a transgenic unc42(e270) mutant expressing both $n m r-1::$ GFP and a wildtype unc-42 genomic clone. Axon outgrowth is indistinguishable from that of wild-type worms. $F$, Wildtype worm that expressed $n m r-1:: G F P$. All images show the head region only, with anterior on the left and more posterior regions on the right of each panel. See Figure 5 for the identity of neurons that express $n m r-1:: G F P$. $G$, Processes of the ventral cord in an $n m r-1:: G F P$; unc42(e270) mutant. Only four processes were visible in the ventral cord (three of these indicated by arrows), whereas nine are expected in a wild-type worm. Migration of a subset of the processes terminated prematurely in the ventral cord (arrowhead). H, I, Schematic diagram of the locomotory control circuit in wild-type $(H)$ and unc-42 mutants $(I)$. The circuits have been divided into forward (black) and backward ( gray) components. Gap junctions and chemical synapses between sensory neurons (triangles), command interneurons (hexagons), and motor neurons (circles) are represented by lines and arrows, respectively. In wild-type worms $(H)$ the DA motor neurons that direct backward movement receive synaptic input from the backward command interneurons (AVA, AVD, and AVE). In unc-42 mutants $(I)$ these connections are disrupted, and the worms have difficulty moving backward. Note that both the forward and backward command interneurons receive synaptic input from sensory neurons (AVM and ASH) that normally drive backward movement in response to anterior tactile stimulation. Scale bars, $5 \mu \mathrm{m}$.

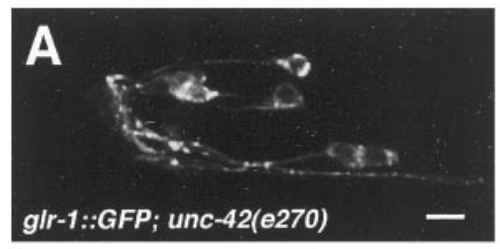

D

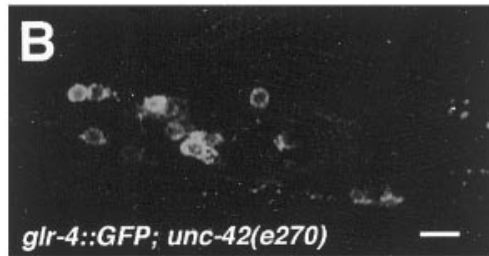

E

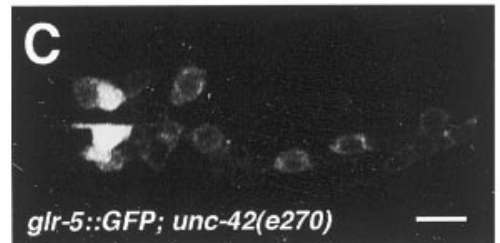

$\mathbf{F}$
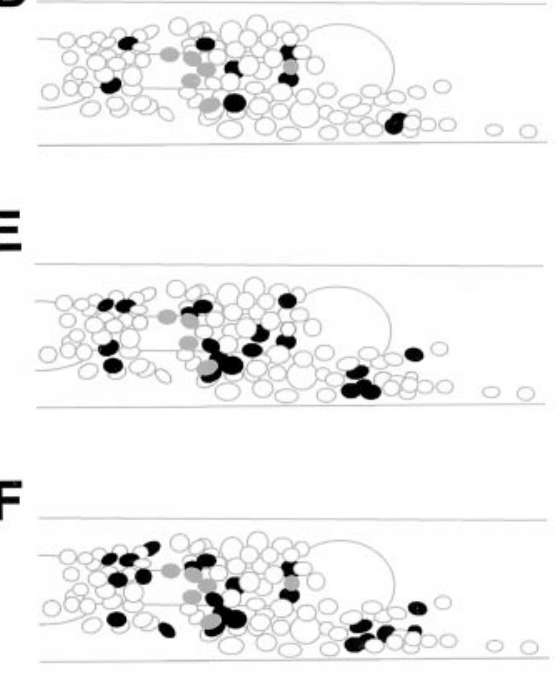
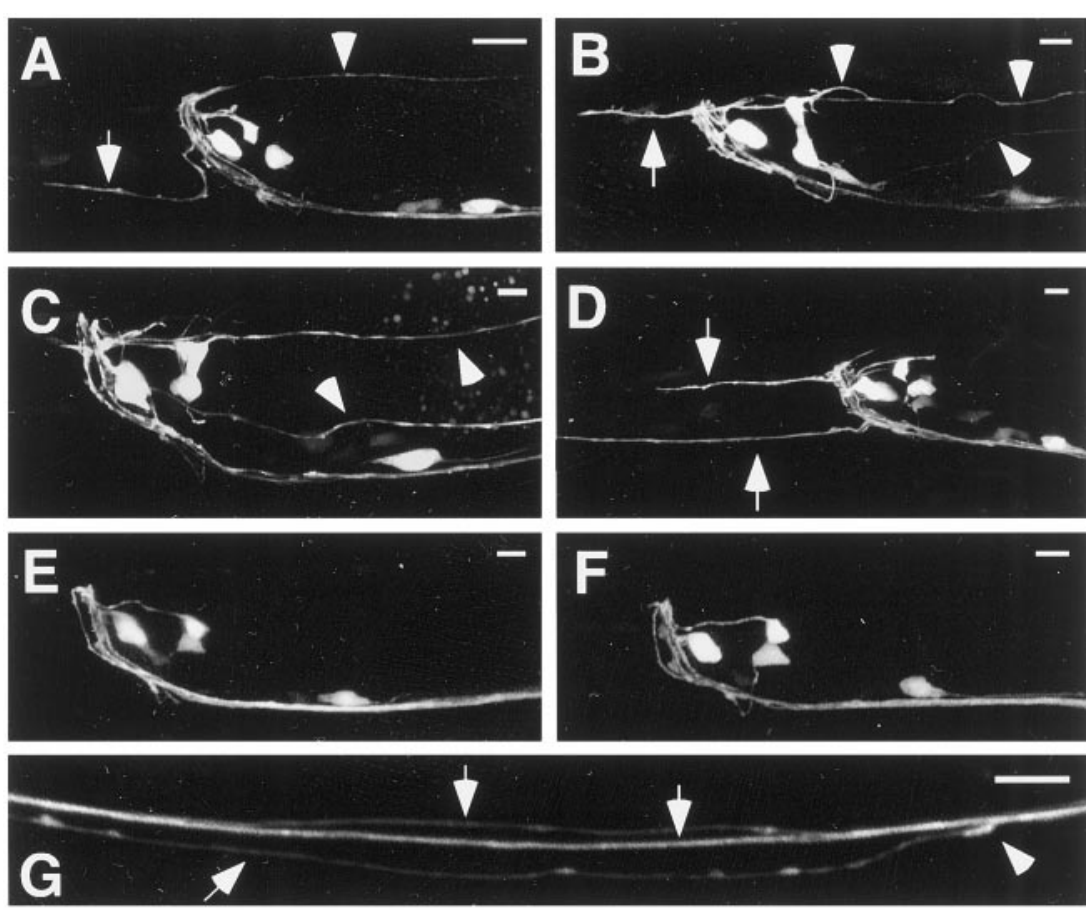

H
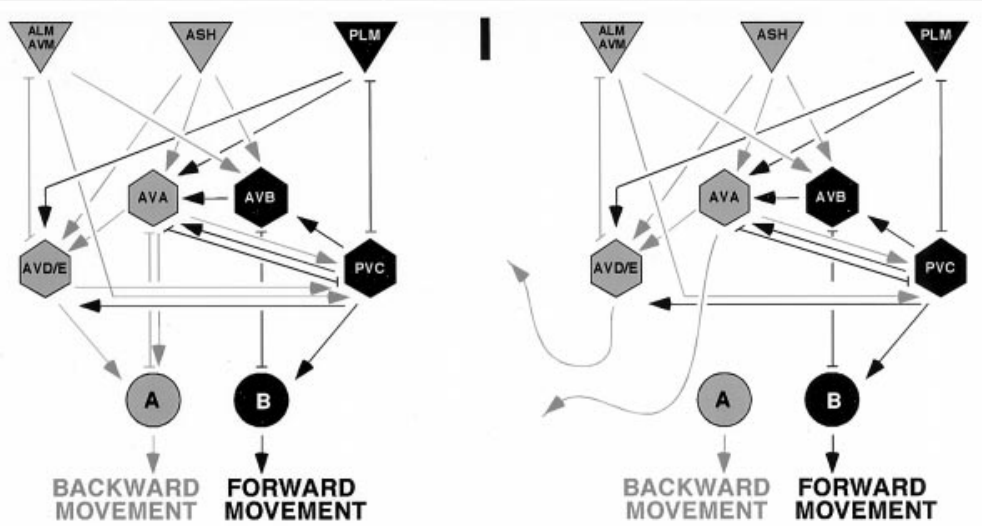
Table 3. unc-42 behavioral defects

\begin{tabular}{llllr} 
& $\begin{array}{l}\text { Anterior } \\
\text { touch back } \\
\text { (forward) }\end{array}$ & $\begin{array}{l}\text { Posterior } \\
\text { touch } \\
\text { forward }\end{array}$ & $\begin{array}{l}\text { Nose } \\
\text { touch } \\
\text { back }\end{array}$ & $\begin{array}{l}\text { Velocity } \\
\text { (bend/min) }\end{array}$ \\
\hline Wild type & $100 \%(0 \%)$ & $95 \%$ & $88 \pm 3.6 \%$ & $19.5 \pm 1.0$ \\
unc-42 (e270) & $5 \%(70 \%)$ & $95 \%$ & $28 \pm 5.1 \%$ & $3.0 \pm 0.5$ \\
unc-42 (rescue) & $90 \%(5 \%)$ & $100 \%$ & $83 \pm 3.7 \%$ & $21.0 \pm 1.5$
\end{tabular}

Body touch $(n=20)$, nose touch $(n=10)$, and velocity $(n=10)$ were assayed as described in Materials and Methods. The percentage of forward movement in response to anterior touch is indicated in parentheses. Complete rescue of anterior and posterior touch response, nose touch response, and velocity (coordination) was observed in transgenic $u n c-42$ worms that express UNC-42. Data are expressed as the mean \pm SEM.

\begin{tabular}{|c|c|c|c|c|}
\hline & $\begin{array}{l}\text { Total axon } \\
\text { defects }(\%)\end{array}$ & $\begin{array}{l}\text { Lateral } \\
\text { cord }(\%)\end{array}$ & $\begin{array}{l}\text { Dorsal } \\
\text { cord }(\%)\end{array}$ & $\begin{array}{l}\text { Anterior to } \\
\text { nerve ring }(\%)\end{array}$ \\
\hline Wild type & 0 & 0 & 0 & 0 \\
\hline unc-42(e270) & 95 & 30 & 40 & 55 \\
\hline unc-42(e419) & 95 & 30 & 50 & 70 \\
\hline unc-42 (rescue) & 5 & 0 & 5 & 0 \\
\hline
\end{tabular}

Axon outgrowth defects were evaluated by inspection of confocal images of transgenic strains that express $n m r-1:: G F P$. Twenty worms were scored for each strain.

neurons were killed either by a laser (Chalfie et al., 1985) or by specific expression of a caspase (Zheng et al., 1999), the worms were touch insensitive and uncoordinated. The severe axon outgrowth defects observed in the backward command interneurons in $u n c-42$ mutants are predicted to be incompatible with normal neuronal signaling and therefore should phenocopy the sensory and motor defects observed with neuronal ablation. The requirement reported by Baran et al. (1999) for expression in the AB.p cell lineage suggests that UNC-42 function may be required in AVE(R) or that low levels of UNC-42 are expressed in RIM. Ablation of RIM suggests that it may also have a role in touch response and coordinating backward and forward locomotion (Zheng et al., 1999).

UNC-42 is also expressed in the ASH sensory neurons that are required for the nose touch response. However, the processes of these neurons are not disrupted in $u n c-42$ mutants (Baran et al., 1999), suggesting that the nose touch defect observed in unc-42 mutants is caused by a postsynaptic defect. We provide evidence of a postsynaptic mechanism by showing that processes of AVA, AVD, and AVE are disrupted in unc-42 mutants.

The forward movement of unc-42 mutants is disrupted, although the forward command interneurons do not express UNC-42 and their processes are normal in unc-42 mutants. These results support a model in which the function of the command interneurons is, in part, distributed (Zheng et al., 1999). unc-42 mutants move forward in response to posterior touch, and paradoxically, they also often move forward in response to anterior touch. This result can be explained by the known wiring of the body wall touch receptors (Fig. 10H,I) (Chalfie et al., 1985; White et al., 1986). The anterior touch receptors make synaptic contacts with both the forward and backward command interneurons (Fig. $10 H)$. Presumably, only contacts to the backward circuit are disrupted in unc-42 mutants, leaving contacts to the forward circuit intact (Fig. 10I). Consequently, the worms move forward rather than backward in response to anterior touch. Our results show that the initiation of an appropriate forward or backward response is dependent on subsets of the command interneurons but that coordinated forward or backward movement requires an intact circuit that contains all of the command interneurons (Zheng et al., 1999).

\section{Summary}

In a small and relatively simple nervous system, such as that found in $C$. elegans, single neurons perform many tasks undertaken by ensembles of neurons in larger nervous systems. For example, the amphid sensory neurons that detect olfactory cues express numerous genes encoding odorant receptors, whereas in the vertebrate olfactory system each neuron is thought to express only one specific receptor (Chess et al., 1994; Troemel et al., 1995). A situation similar to that of amphid sensory neurons may exist for interneurons in the $C$. elegans nervous system. The small number of command interneurons receives a large number of synaptic inputs from sensory neurons and interneurons and integrates this information to direct locomotory output. These neurons also express a large assortment of glutamate receptor subunits. Presumably, this diversity of subunits is required in part for the integrative function of these interneurons. The expression pattern of glutamate receptor subunits suggests that they may have critical roles in the control of locomotory response, pharyngeal function, and sensory processing. How these subunits are partitioned within neurons and how they function to control neuronal function await more detailed cell biological and electrophysiological analyses.

Note added in proof. Several recent reviews have addressed the predicted glutamate receptors that were identified by the C. elegans genome sequencing consortium. These reviews have used different receptor nomenclatures. Littleton and Ganetsky (2000) used the names of the cosmids that contained the receptor sequences. Hollmann (1999) and Sprengel et al. (2001) assigned names somewhat different than those we use here. Our nomenclature follows that introduced by Maricq et al. (1995) and Hart et al. (1995) and is based on the sequences of the cloned cDNAs.

\section{REFERENCES}

Albertson DG, Thomson JN (1976) The pharynx of Caenorhabditis elegans. Philos Trans R Soc Lond [Biol] 275:299-325.

Altschul SF, Madden TL, Schaffer AA, Zhang J, Zhang Z, Miller W, Lipman DJ (1997) Gapped BLAST and PSI-BLAST: a new generation of protein database search programs. Nucleic Acids Res 25:3389-3402.

Armstrong N, Sun Y, Chen GQ, Gouaux E (1998) Structure of a glutamate-receptor ligand-binding core in complex with kainate. Nature 395:913-917.

Baran R, Aronoff R, Garriga G (1999) The C. elegans homeodomain gene unc-42 regulates chemosensory and glutamate receptor expression. Development 126:2241-2251.

Bellocchio EE, Reimer RJ, Fremeau Jr RT, Edwards RH (2000) Uptake of glutamate into synaptic vesicles by an inorganic phosphate transporter [see comments]. Science 289:957-960.

Burnashev N, Monyer H, Seeburg PH, Sakmann B (1992) Divalent ion permeability of AMPA receptor channels is dominated by the edited form of a single subunit. Neuron 8:189-198.

Chalfie M, Sulston JE, White JG, Southgate E, Thomson JN, Brenner S (1985) The neural circuit for touch sensitivity in Caenorhabditis elegans. J Neurosci 5:956-964.

Chalfie M, Tu Y, Euskirchen G, Ward WW, Prasher DC (1994) Green fluorescent protein as a marker for gene expression. Science 263:802-805.

Chess A, Simon I, Cedar H, Axel R (1994) Allelic inactivation regulates olfactory receptor gene expression. Cell 78:823-834.

Clark SG, Lu X, Horvitz HR (1994) The Caenorhabditis elegans locus lin-15, a negative regulator of a tyrosine kinase signaling pathway, encodes two different proteins. Genetics 137:987-997.

Dingledine R, Borges K, Bowie D, Traynelis SF (1999) The glutamate receptor ion channels. Pharmacol Rev 51:7-61.

Dunah AW, Luo J, Wang YH, Yasuda RP, Wolfe BB (1998) Subunit composition of $N$-methyl-D-aspartate receptors in the central nervous system that contain the NR2D subunit. Mol Pharmacol 53:429-437. 
Felsenstein J (1989) PHYLIP-phylogeny inference package (version 3.2). Cladistics 5:164-166.

Gomperts SN, Carroll R, Malenka RC, Nicoll RA (2000) Distinct roles for ionotropic and metabotropic glutamate receptors in the maturation of excitatory synapses. J Neurosci 20:2229-2237.

Hart AC, Sims S, Kaplan JM (1995) Synaptic code for sensory modalities revealed by $C$. elegans GLR-1 glutamate receptor. Nature 378:82-85.

Hollmann M (1999) Structure of ionotropic glutamate receptors. In: Ionotropic glutamate receptors in the CNS (Jonas P, Monyer H, eds), pp 1-98. Berlin: Springer.

Hollmann M, Maron C, Heinemann S (1994) N-glycosylation site tagging suggests a three transmembrane domain topology for the glutamate receptor GluR1. Neuron 13:1331-1343.

Hume RI, Dingledine R, Heinemann SF (1991) Identification of a site in glutamate receptor subunits that controls calcium permeability. Science 253:1028-1031.

Kaplan JM, Horvitz HR (1993) A dual mechanosensory and chemosensory neuron in Caenorhabditis elegans. Proc Natl Acad Sci USA 90:2227-2231.

Kimura M (1983) The neutral theory of molecular evolution. Cambridge, UK: Cambridge UP.

Kuryatov A, Laube B, Betz H, Kuhse J (1994) Mutational analysis of the glycine-binding site of the NMDA receptor: structural similarity with bacterial amino acid-binding proteins. Neuron 12:1291-1300.

Lam HM, Chiu J, Hsieh MH, Meisel L, Oliveira IC, Shin M, Coruzzi G (1998) Glutamate-receptor genes in plants [letter]. Nature 396:125-126.

Landsend AS, Amiry-Moghaddam M, Matsubara A, Bergersen L, Usami S, Wenthold RJ, Ottersen OP (1997) Differential localization of delta glutamate receptors in the rat cerebellum: coexpression with AMPA receptors in parallel fiber-spine synapses and absence from climbing fiber-spine synapses. J Neurosci 17:834-842.

Lee RY, Sawin ER, Chalfie M, Horvitz HR, Avery L (1999) EAT-4, a homolog of a mammalian sodium-dependent inorganic phosphate cotransporter, is necessary for glutamatergic neurotransmission in Caenorhabditis elegans. J Neurosci 19:159-167.

Liao D, Hessler NA, Malinow R (1995) Activation of postsynaptically silent synapses during pairing-induced LTP in CA1 region of hippocampal slice. Nature 375:400-404.

Littleton JT, Ganetzky B (2000) Ion channels and synaptic organization: analysis of the Drosophila genome. Neuron 26:35-43.

Maricq AV, Peckol E, Driscoll M, Bargmann CI (1995) Mechanosensory signalling in $C$. elegans mediated by the GLR-1 glutamate receptor. Nature 378:78-81.

Mello CC, Kramer JM, Stinchcomb D, Ambros V (1991) Efficient gene transfer in $C$. elegans: extrachromosomal maintenance and integration of transforming sequences. EMBO J 10:3959-3970.

Mori I, Ohshima Y (1995) Neural regulation of thermotaxis in Caenorhabditis elegans. Nature 376:344-348.

Nakanishi N, Shneider N, Axel R (1990) A family of glutamate receptor genes: evidence for the formation of heteromultimeric receptors with distinct channel properties. Neuron 5:569-581.

O'Brien RJ, Mammen AL, Blackshaw S, Ehlers MD, Rothstein JD, Huganir RL (1997) The development of excitatory synapses in cultured spinal neurons. J Neurosci 17:7339-7350.

Paternain AV, Herrera MT, Nieto MA, Lerma J (2000) GluR5 and GluR6 kainate receptor subunits coexist in hippocampal neurons and coassemble to form functional receptors. J Neurosci 20:196-205.

Petralia RS, Wenthold RJ (1996) Types of excitatory amino acid receptors and their localization in the nervous system and hypothalamus. In: Excitatory amino acids: their role in neuroendocrine function (Brann DW, Mahesh VB, eds), pp 55-101. New York: CRC.

Petralia RS, Esteban JA, Wang YX, Partridge JG, Zhao HM, Wenthold RJ, Malinow R (1999a) Selective acquisition of AMPA receptors over postnatal development suggests a molecular basis for silent synapses. Nat Neurosci 2:31-36.
Petralia RS, Rubio ME, Wenthold RJ (1999b) Cellular and subcellular distribution of glutamate receptors. In: Ionotropic glutamate receptors in the CNS (Jonas P, Monyer H, eds), pp 143-171. Berlin: Springer.

Premkumar LS, Auerbach A (1997) Stoichiometry of recombinant $N$-methyl-D-aspartate receptor channels inferred from single-channel current patterns. J Gen Physiol 110:485-502.

Raizen DM, Avery L (1994) Electrical activity and behavior in the pharynx of Caenorhabditis elegans. Neuron 12:483-495.

Rao A, Craig AM (1997) Activity regulates the synaptic localization of the NMDA receptor in hippocampal neurons. Neuron 19:801-812.

Rongo C, Whitfield CW, Rodal A, Kim SK, Kaplan JM (1998) LIN-10 is a shared component of the polarized protein localization pathways in neurons and epithelia. Cell 94:751-759.

Rosenmund C, Stern-Bach Y, Stevens CF (1998) The tetrameric structure of a glutamate receptor channel [see comments]. Science 280:1596-1599.

Rubio ME, Wenthold RJ (1997) Glutamate receptors are selectively targeted to postsynaptic sites in neurons. Neuron 18:939-950.

Shi SH, Hayashi Y, Petralia RS, Zaman SH, Wenthold RJ, Svoboda K, Malinow R (1999) Rapid spine delivery and redistribution of AMPA receptors after synaptic NMDA receptor activation [see comments]. Science 284:1811-1816.

Sommer B, Kohler M, Sprengel R, Seeburg PH (1991) RNA editing in brain controls a determinant of ion flow in glutamate-gated channels. Cell 67:11-19

Sprengel R, Aronoff R, Völkner M, Schmitt B, Mosbach R, Kuner T (2001) Glutamate receptor channel signatures. Trends Pharmacol Sci, in press.

Stern-Bach Y, Bettler B, Hartley M, Sheppard PO, O'Hara PJ, Heinemann SF (1994) Agonist selectivity of glutamate receptors is specified by two domains structurally related to bacterial amino acid-binding proteins. Neuron 13:1345-1357.

Takamori S, Rhee JS, Rosenmund C, Jahn R (2000) Identification of a vesicular glutamate transporter that defines a glutamatergic phenotype in neurons [see comments]. Nature 407:189-194.

Takumi Y, Matsubara A, Rinvik E, Ottersen OP (1999a) The arrangement of glutamate receptors in excitatory synapses. Ann NY Acad Sci $868: 474-482$

Takumi Y, Ramirez-Leon V, Laake P, Rinvik E, Ottersen OP (1999b) Different modes of expression of AMPA and NMDA receptors in hippocampal synapses. Nat Neurosci 2:618-624.

Thompson JD, Higgins DG, Gibson TJ (1994) CLUSTAL W: improving the sensitivity of progressive multiple sequence alignment through sequence weighting, position-specific gap penalties and weight matrix choice. Nucleic Acids Res 22:4673-4680.

Troemel ER, Chou JH, Dwyer ND, Colbert HA, Bargmann CI (1995) Divergent seven transmembrane receptors are candidate chemosensory receptors in C. elegans. Cell 83:207-218.

Verdoorn T, Burnashev N, Monyer H, Seeburg P, Sakmann B (1991) Structural determinants of ion flow through recombinant glutamate receptor channels. Science 252:1715-1718.

Wenthold RJ, Roche KW (1998) The organization and regulation of non-NMDA receptors in neurons. Prog Brain Res 116:133-152.

White JG, Southgate E, Thomson JN, Brenner S (1986) The structure of the nervous system of the nematode Caenorhabditis elegans. Philos Trans R Soc Lond [Biol] 314:1-340.

Wightman B, Clark SG, Taskar AM, Forrester WC, Maricq AV, Bargmann CI, Garriga G (1996) The C. elegans gene vab-8 guides posteriorly directed axon outgrowth and cell migration. Development 122:671-682

Zheng Y, Brockie PJ, Mellem JE, Madsen DM, Maricq AV (1999) Neuronal control of locomotion in C. elegans is modified by a dominant mutation in the GLR-1 ionotropic glutamate receptor. Neuron $24: 347-361$.

Zuo J, De Jager PL, Takahashi KA, Jiang W, Linden DJ, Heintz N (1997) Neurodegeneration in Lurcher mice caused by mutation in delta2 glutamate receptor gene [see comments]. Nature 388:769-773. 